Supporting information for

\title{
Revealing hydrogen evolution performance of single-atom platinum electrocatalyst with polyoxometalate molecular models
}

Fei-Yang $\mathrm{Yu}^{1,2}$, Zhong-Ling Lang ${ }^{1 \#}$, Yun-Jie Zhou ${ }^{3 \#}$, Kun Feng ${ }^{3}$, Hua-Qiao Tan ${ }^{1 *}$, Jun Zhong ${ }^{3}$, Shuit-Tong Lee ${ }^{2,3 *}$, Zhen-Hui Kang ${ }^{2,3 *}$, Yang-Guang Li ${ }^{1,4 *}$

${ }^{1}$ Key Laboratory of Polyoxometalate and Reticular Material Chemistry of Ministry of Education, Faculty of Chemistry, Northeast Normal University, Changchun, 130024, China.

${ }^{2}$ Macao Institute of Materials Science and Engineering, Macau University of Science and Technology, Taipa 999078, Macau SAR, China.

${ }^{3}$ Jiangsu Key Laboratory for Carbon-based Functional Materials and Devices, Institute of Functional Nano and Soft Materials (FUNSOM), Soochow University, Suzhou 215123, China.

${ }^{4}$ Key Laboratory of Preparation and Application of Environmental Friendly Materials, Ministry of Education, Jilin Normal University, Changchun, 130103, China.

\section{AUTHOR INFORMATION}

\section{Corresponding Author}

E-mail: H. Q. T: tanhq870@nenu.edu.cn. (H. Q. T)

E-mail: S. T. L: apannale@suda.edu.cn. (S. T. L)

E-mail: Z. H. K: zhkang@must.edu.mo. (Z. H. K)

E-mail: Y. G. L: liyg658@nenu.edu.cn. (Y. G. L) 


\section{EXPERIMENTAL METHODS}

Materials and Methods

Chemicals

$\mathrm{Na}_{2} \mathrm{Pt}(\mathrm{OH})_{6}, \mathrm{Na}_{2} \mathrm{WO}_{4} \cdot 2 \mathrm{H}_{2} \mathrm{O}, \mathrm{K}_{2} \mathrm{MoO}_{4}, \mathrm{NaVO}_{3}$, Ketjen black carbon and Nafion solution (5 wt\%) were purchased from Aladdin Industrial Co., Ltd. and Alfa Aesar China (Tianjin) Co., Ltd, respectively. All solution used in experiments were collected with Millipore water (18.fe2 $\mathrm{M} \Omega$ ). All reagents are of high purity grade.

Synthesis of Pt-POMs/C

The $\left\{\mathrm{PtW}_{6}\right\} / \mathrm{C},\left\{\mathrm{PtMo}_{6}\right\} / \mathrm{C},\left\{\mathrm{PtV}_{9}\right\} / \mathrm{C}$ and $\left\{\mathrm{PtSiW}_{11}\right\} / \mathrm{C}$ catalysts were synthesized with $65 \mathrm{mg} \quad \mathrm{Na}_{5}\left[\mathrm{H}_{3} \mathrm{PtW}_{6} \mathrm{O}_{24}\right], \quad 30 \quad \mathrm{mg} \quad \mathrm{K}_{4}\left[\mathrm{H}_{4} \beta-\mathrm{PtMo}_{6} \mathrm{O}_{24}\right] \cdot 2 \mathrm{H}_{2} \mathrm{O}, \quad 50 \quad \mathrm{mg}$ $\mathrm{Na}_{5}\left[\mathrm{H}_{2} \mathrm{PtV}_{9} \mathrm{O}_{28}\right] \cdot 21 \mathrm{H}_{2} \mathrm{O}, 62 \mathrm{mg}\left[\left(\mathrm{C}_{3} \mathrm{H}_{9}\right)_{4} \mathrm{~N}\right]_{4}\left[\mathrm{SiPtW}_{11} \mathrm{O}_{40} \mathrm{H}_{2}\right]$, and $5 \mathrm{mg}$ Ketjen black carbon as raw materials, respectively. Typically, the POM crystal and Ketjen black carbon was homogeneous dispersed in $1 \mathrm{~mL} \mathrm{H}_{2} \mathrm{O}$, stirring two hours at ambient temperature. $10 \mu \mathrm{L}$ of Nafion was put into the obtained aqueous and stirred four hours. The four electrocatalysts can be collected by centrifuge and dried at room temperature.

\section{Characterization}

Powder X-ray diffraction (PXRD) measurements were performed on a Rigaku D/maxIIB X-ray diffractometer with $\mathrm{Cu}-\mathrm{K} \alpha$ radiation $(\lambda=1.5418 \AA)$. Scanning transmission electron microscopy (STEM) images were tested on HF5000 and Titan Cubed Themis G2 300 equipped with a probe corrector. Transmission electron microscopy (TEM) images were carried out on JEOL-2100F with an accelerating voltage of $200 \mathrm{kV}$. The X-ray photoelectron spectroscopy (XPS) instruments were carried out on a KRATOS 
Axis ultra DLD X-ray photoelectron spectrometer at a monochromatized $\mathrm{Mg} \mathrm{K \alpha}$ X-ray source $(h v=1283.3 \mathrm{eV})$. X-ray absorption near edge structure (XANES) and extended X-ray absorption fine structure (EXAFS) data were tried out on the BL11B beamline at the Shanghai Synchrotron Radiation Facility (SSRF), ran at $3.5 \mathrm{GeV}$ at injection currents of 140-210 mA. HER performance and cyclic voltammetry were studied by a CHI760E workstation (CH Instruments, China).

Electrochemical Measurements

HER test

HER performance was carried out in $\mathrm{N}_{2}$-saturated $0.5 \mathrm{M} \mathrm{H}_{2} \mathrm{SO}_{4}$ with a conventional three-electrode electrochemical system at $300 \mathrm{~K}$. A carbon rod and a saturated calomel electrode (SCE) used as counter electrode and reference electrode, respectively. The working electrode was modified glassy carbon electrode $(d=3 \mathrm{~mm})$. Polarization curves were tried out at $5 \mathrm{mV} \mathrm{s}^{-1}$. The obtained potentials vs. SCE were standardized with a reversible hydrogen electrode (RHE) with $\mathrm{E} v s . \mathrm{RHE}=\mathrm{E}^{\theta}{ }_{\mathrm{SCE}}+0.059 \mathrm{pH}\left(\mathrm{E}_{\mathrm{SCE}}^{\theta}\right.$ $=0.242 \mathrm{~V})$. All data were checked with $I R$ compensation. The accelerated degradation test was carried out by $\mathrm{CV}$ with $100 \mathrm{mV} / \mathrm{s}$. The long-term stability was tested at controlled potential.

Cyclic voltammetry

The electrolyte was $\mathrm{CH}_{3} \mathrm{CN}$ with $0.05 \mathrm{M}$ tetrabutylammonium perchlorate, which was deoxygenated with pure nitrogen thoroughly for $30 \mathrm{~min}$ and remained under a positive pressure of pure nitrogen during the $\mathrm{CV}$ tests. The counter electrode was the platinum wire. Non-aqueous $\mathrm{Ag} / \mathrm{Ag}^{+}$electrode served as reference electrode, which was filled 
the $0.01 \mathrm{M} \mathrm{AgNO}_{3} / \mathrm{CH}_{3} \mathrm{CN}$. The bare glassy carbon was employed as the working electrode.

Computational Details

Following the computational strategies applied to $\left\{\mathrm{PtW}_{6}\right\}$ system in our previous work, additional systems of $\left\{\mathrm{PtMo}_{6}\right\},\left\{\mathrm{PV}_{9}\right\}$ and $\left\{\mathrm{PtSiW}_{11}\right\}$ were optimized and frequency characterized at the same theoretical level of $(\mathrm{U}) \mathrm{M} 06 / \mathrm{PCM}\left(\mathrm{H}_{2} \mathrm{O}\right) /[6-31 \mathrm{G}(\mathrm{d}, \mathrm{p})(\mathrm{O}, \mathrm{H}$, $\mathrm{Si}) / \mathrm{LANL} 2 \mathrm{DZ}(\mathrm{Pt} \& W)]$. All energies were finally corrected at $(\mathrm{U}) \mathrm{M} 06 / \mathrm{PCM}\left(\mathrm{H}_{2} \mathrm{O}\right) /[6-$ $311++\mathrm{G}(\mathrm{d}, \mathrm{p}) / \mathrm{SDD}(\mathrm{Pt} \& \mathrm{~W})]$ level. A data set of computational results for $\left\{\mathrm{PtMo}_{6}\right\}$, $\left\{\mathrm{PV}_{9}\right\}$ and $\left\{\mathrm{PtSiW}_{11}\right\}$ related systems is available in the ioChem-BD repository and can be accessed via https://doi.org/10.19061/iochem-bd-6-27 (http://www.iochembd.org/) 


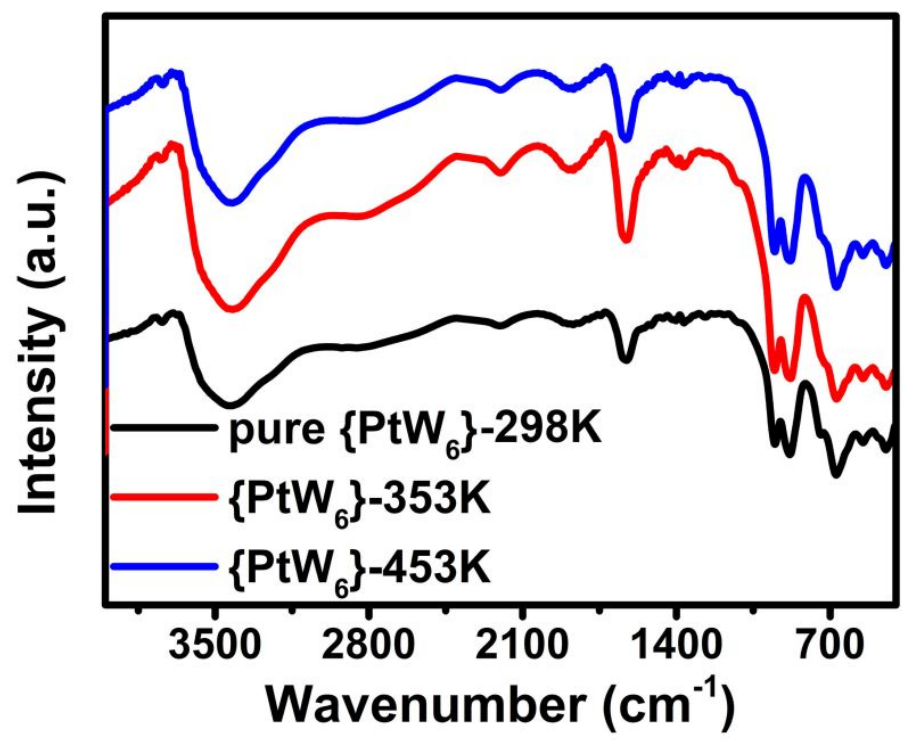

Figure S1. The IR curves of $\left\{\mathrm{PtW}_{6}\right\}$ at different temperature for $24 \mathrm{~h}$. 


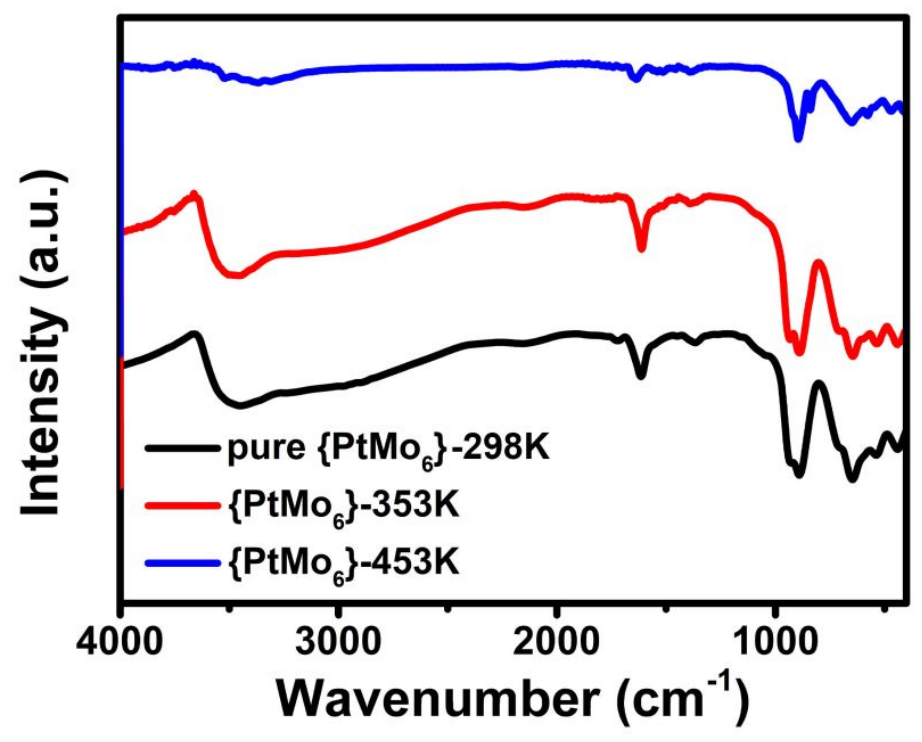

Figure S2. The IR curves of $\left\{\mathrm{PtMo}_{6}\right\}$ at different temperature for $24 \mathrm{~h}$. 


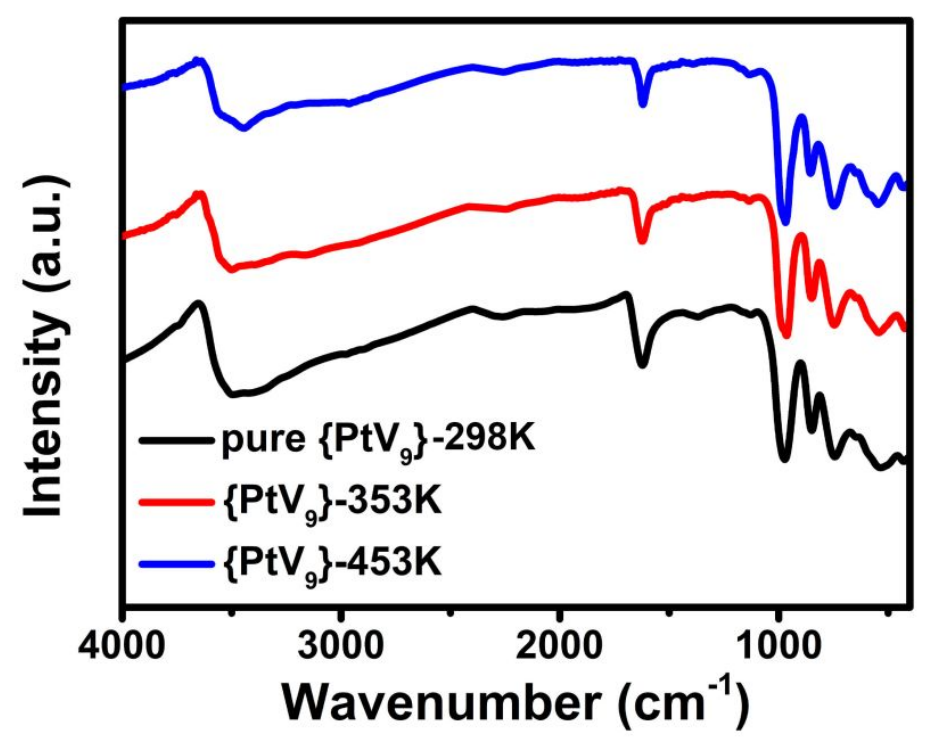

Figure S3. The IR curves of $\left\{\mathrm{PtV}_{9}\right\}$ at different temperature for $24 \mathrm{~h}$. 


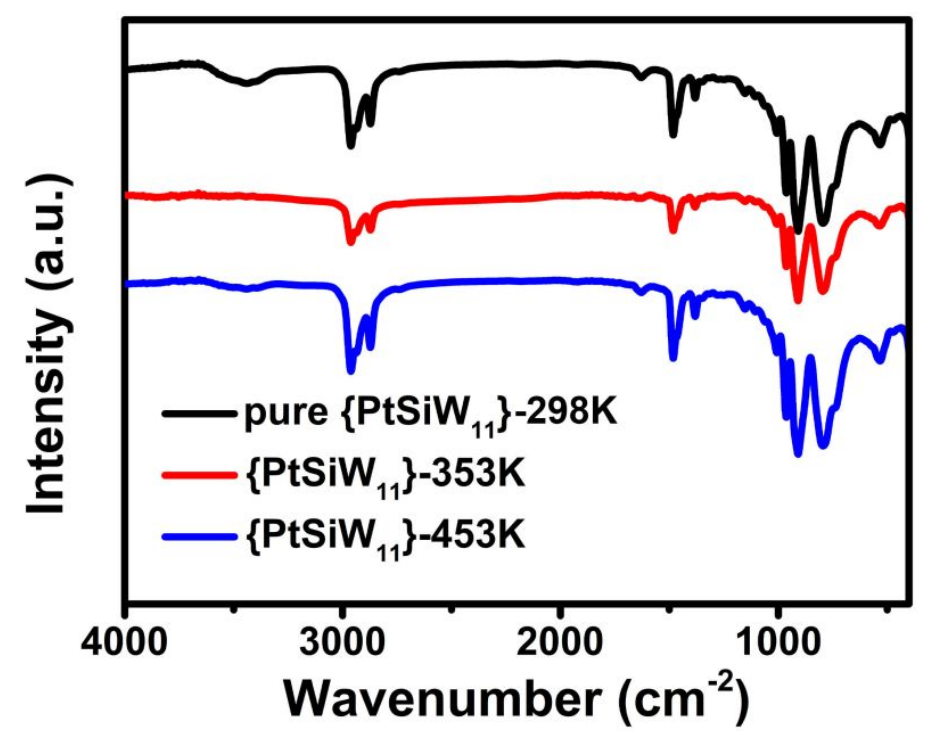

Figure S4. The IR curves of $\left\{\mathrm{PtSiW}_{11}\right\}$ at different temperature for $24 \mathrm{~h}$. 


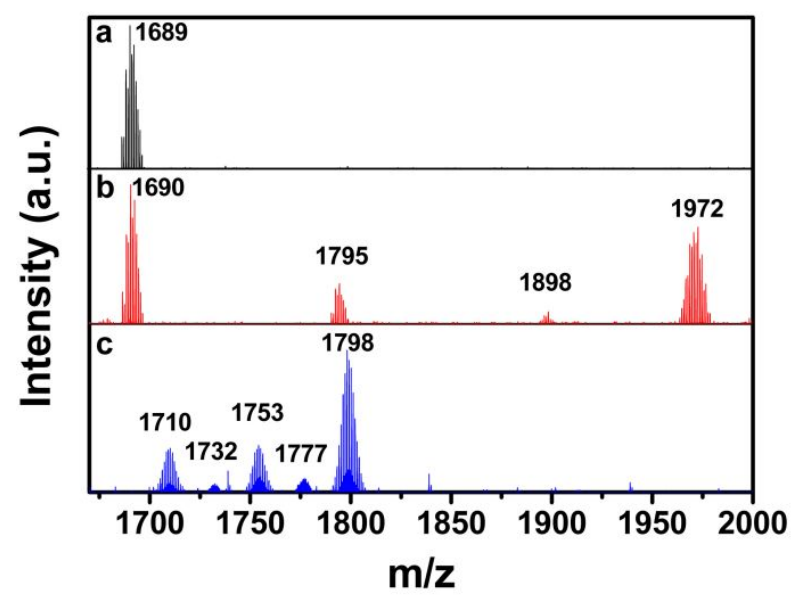

Figure S5. The electrospray-ionization mass spectra (EIS) of $\left\{\mathrm{PtW}_{6}\right\}$ compound before and after HER in $0.5 \mathrm{M} \mathrm{H}_{2} \mathrm{SO}_{4}$ aqueous solution as well as its re-oxidized species by $\mathrm{Br}_{2}$. The test samples are prepared by precipitating the polyoxoanion with tetrabutylammonium (TBA) bromide and dissolved in $\mathrm{CH}_{3} \mathrm{CN}$. (a) Before HER, the signals of $\mathrm{m} / \mathrm{z}=1689$ can be assigned to $\mathrm{H}_{4}\left[\mathrm{Pt}^{\mathrm{IV}} \mathrm{W}_{6} \mathrm{O}_{24} \mathrm{H}_{3}\right]^{-}$species. (b) After $\mathrm{PtW}_{6} \mathrm{O}_{24}$ catalyst has undergone HER for 10 cycles in $0.5 \mathrm{M} \mathrm{H}_{2} \mathrm{SO}_{4}$ aqueous solution, the signals of $\mathrm{m} / \mathrm{z}=1690, \mathrm{~m} / \mathrm{z}=1795, \mathrm{~m} / \mathrm{z}=1898$, and $\mathrm{m} / \mathrm{z}=1972$ can be assigned to $\mathrm{H}_{4}\left[\mathrm{Pt}^{\mathrm{II}} \mathrm{W}_{6} \mathrm{O}_{24} \mathrm{H}_{5}\right]^{-}, \quad \quad \mathrm{NaH}_{3}\left[\mathrm{Pt}^{\mathrm{II}} \mathrm{W}_{6} \mathrm{O}_{24} \mathrm{H}_{5}\right]^{-} \cdot\left(\mathrm{CH}_{3} \mathrm{CN}\right)_{2}$, $\mathrm{Na}_{4}\left[\mathrm{Pt}^{\mathrm{II}} \mathrm{W}_{6} \mathrm{O}_{24} \mathrm{H}_{5}\right]^{-\cdot} \cdot\left(\mathrm{CH}_{3} \mathrm{CN}\right)_{2}\left(\mathrm{H}_{2} \mathrm{O}\right)_{2}$, and (TBA) $\mathrm{NaH}_{2}\left[\mathrm{Pt}^{\mathrm{II}} \mathrm{W}_{6} \mathrm{O}_{24} \mathrm{H}_{5}\right]^{-} \cdot \mathrm{CH}_{3} \mathrm{CN}$ species, respectively. (c) When the molecular catalyst was re-oxidized by $\mathrm{Br}_{2}$ in above solution, the signals of $\mathrm{m} / \mathrm{z}=1710, \mathrm{~m} / \mathrm{z}=1732, \mathrm{~m} / \mathrm{z}=1753, \mathrm{~m} / \mathrm{z}=1777$ and $\mathrm{m} / \mathrm{z}=1798 \mathrm{can}$ be assigned to $\mathrm{NaH}_{3}\left[\mathrm{Pt}^{\mathrm{IV}} \mathrm{W}_{6} \mathrm{O}_{24} \mathrm{H}_{3}\right]^{-}, \mathrm{Na}_{2} \mathrm{H}_{2}\left[\mathrm{Pt}^{\mathrm{IV}} \mathrm{W}_{6} \mathrm{O}_{24} \mathrm{H}_{3}\right]^{-}, \mathrm{NaH}_{3}\left[\mathrm{Pt}^{\mathrm{IV}} \mathrm{W}_{6} \mathrm{O}_{24} \mathrm{H}_{3}\right]^{-} \cdot \mathrm{CH}_{3} \mathrm{CN}$, $\mathrm{Na}_{4}\left[\mathrm{Pt}^{\mathrm{IV}} \mathrm{W}_{6} \mathrm{O}_{24} \mathrm{H}_{3}\right]^{-}$, and $\mathrm{Na}_{3} \mathrm{H}\left[\mathrm{Pt}^{\mathrm{IV}} \mathrm{W}_{6} \mathrm{O}_{24} \mathrm{H}_{3}\right]^{-} \cdot \mathrm{CH}_{3} \mathrm{CN}$, respectively. The above experiments demonstrate that $\left\{\mathrm{PtW}_{6}\right\}$ compound behaves as a reversible redox-active catalyst. 


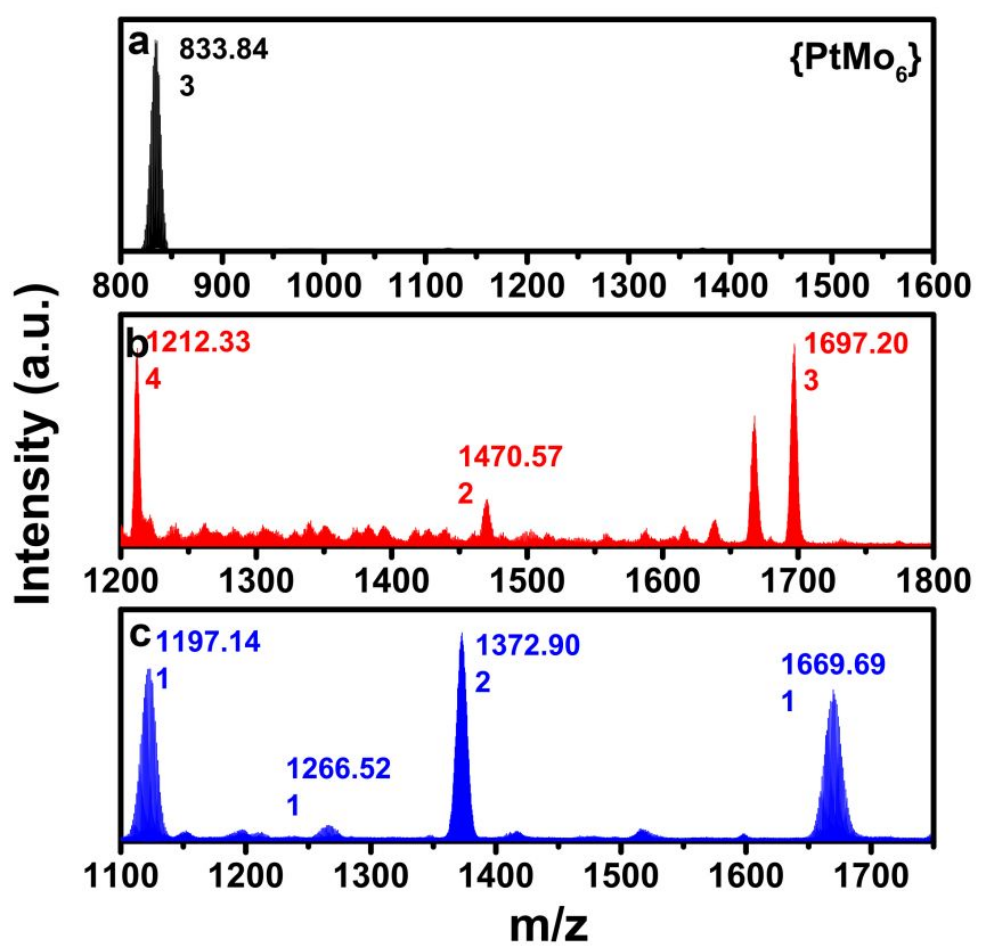

Figure S6. The electrospray-ionization mass spectra (EIS) of $\left\{\mathrm{PtMo}_{6}\right\}$ compound before and after HER in $0.5 \mathrm{M} \mathrm{H}_{2} \mathrm{SO}_{4}$ aqueous solution as well as its re-oxidized species by $\mathrm{Br}_{2}$. The test samples are prepared by precipitating the polyoxoanion with tetrabutylammonium (TBA) bromide and dissolved in $\mathrm{CH}_{3} \mathrm{CN}$. (a) Before HER, the signal of $\mathrm{m} / \mathrm{z}=833.84$ can be assigned to $\mathrm{TBA}\left[\mathrm{PtMo}_{6} \mathrm{O}_{24} \mathrm{H}_{4}\right]^{3-\cdot} \cdot\left(\mathrm{H}_{2} \mathrm{O}\right)_{27}\left(\mathrm{CH}_{3} \mathrm{CN}\right)_{15}$ species. (b) After $\left\{\mathrm{PtMo}_{6}\right\}$ catalyst has undergone HER for 10 cycles in $0.5 \mathrm{M} \mathrm{H}_{2} \mathrm{SO}_{4}$ aqueous solution, the signals of $\mathrm{m} / \mathrm{z}=1212.33, \mathrm{~m} / \mathrm{z}=1470.57$, and $\mathrm{m} / \mathrm{z}=1697.20$ can be assigned to $\left\{\mathrm{TBA}_{2}\left[\mathrm{PtMo}_{6} \mathrm{O}_{24} \mathrm{H}_{6}\right]^{2-\cdot}\left(\mathrm{H}_{2} \mathrm{O}\right)_{16}\left(\mathrm{CH}_{3} \mathrm{CN}\right)_{12}\right\}_{2}$, $\left\{\mathrm{KNa}_{2}\left[\mathrm{PtMo}_{6} \mathrm{O}_{24} \mathrm{H}_{5}\right]^{-\cdot}\left(\mathrm{H}_{2} \mathrm{O}\right)_{8}\left(\mathrm{CH}_{3} \mathrm{CN}\right)_{2}\right\}_{2}$, and $\left\{\mathrm{TBANa}_{2}\left[\mathrm{PtMo}_{6} \mathrm{O}_{24} \mathrm{H}_{5}\right]^{-\cdot}\left(\mathrm{H}_{2} \mathrm{O}\right)_{7}\left(\mathrm{CH}_{3} \mathrm{CN}\right)_{3}\right\}_{3}$ species, respectively. (c) When the molecular catalyst was re-oxidized by $\mathrm{Br}_{2}$ in above solution, the signals of $\mathrm{m} / \mathrm{z}=$ 1197.14, $\mathrm{m} / \mathrm{z}=1266.52, \mathrm{~m} / \mathrm{z}=1372.92$ and $\mathrm{m} / \mathrm{z}=1669.69$ can be assigned to $\mathrm{H}_{3}\left[\mathrm{PtMo}_{6} \mathrm{O}_{24} \mathrm{H}_{4}\right]^{-\cdot}\left(\mathrm{H}_{2} \mathrm{O}\right)_{2}, \quad \mathrm{NaH}_{2}\left[\mathrm{PtMo}_{6} \mathrm{O}_{24} \mathrm{H}_{4}\right]^{-\cdot} \cdot\left(\mathrm{CH}_{3} \mathrm{CN}\right)_{2}, \quad \mathrm{TBA}_{2}\left[\mathrm{PtMo}_{6} \mathrm{O}_{24} \mathrm{H}_{4}\right]$ 2-. $\left(\mathrm{H}_{2} \mathrm{O}\right)_{59}\left(\mathrm{CH}_{3} \mathrm{CN}\right), \quad \mathrm{TBANa}_{2}\left[\mathrm{PtMo}_{6} \mathrm{O}_{24} \mathrm{H}_{4}\right] \cdot\left(\mathrm{H}_{2} \mathrm{O}\right) \quad\left(\mathrm{CH}_{3} \mathrm{CN}\right)_{5}$, respectively. The above experiments demonstrate that $\left\{\mathrm{PtMo}_{6}\right\}$ compound behaves as a reversible redoxactive and stable catalyst. 


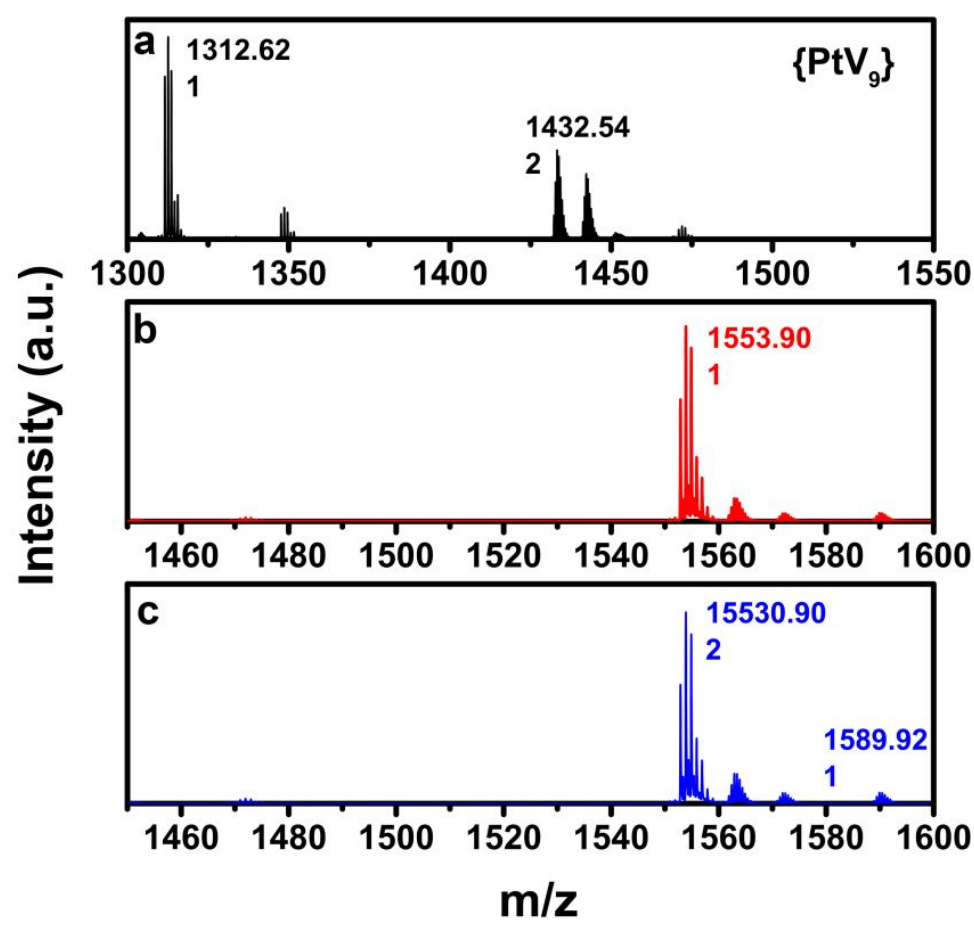

Figure S7. The electrospray-ionization mass spectra (EIS) of $\left\{\mathrm{PtV}_{9}\right\}$ compound before and after HER in $0.5 \mathrm{M} \mathrm{H}_{2} \mathrm{SO}_{4}$ aqueous solution as well as its re-oxidized species by $\mathrm{Br}_{2}$. The test samples are prepared by precipitating the polyoxoanion with tetrabutylammonium (TBA) bromide and dissolved in $\mathrm{CH}_{3} \mathrm{CN}$. (a) Before HER, the signals of $\mathrm{m} / \mathrm{z}=1312.62$ and $\mathrm{m} / \mathrm{z}=1432.54$ can be assigned to $\mathrm{Na}_{4}\left[\mathrm{PtV}_{9} \mathrm{O}_{28} \mathrm{H}_{2}\right]^{-\cdot} \cdot\left(\mathrm{H}_{2} \mathrm{O}\right)_{2}\left(\mathrm{CH}_{3} \mathrm{CN}\right)_{2}$ and $\left\{\mathrm{K}_{2} \mathrm{Na}_{2}\left[\mathrm{PtV}_{9} \mathrm{O}_{28} \mathrm{H}_{2}\right]^{2-\cdot}\left(\mathrm{CH}_{3} \mathrm{CN}\right)_{5}\right\}_{2}$ species. (b) After $\left\{\mathrm{PtV}_{9}\right\}$ catalyst has undergone HER for 10 cycles in $0.5 \mathrm{M} \mathrm{H}_{2} \mathrm{SO}_{4}$ aqueous solution, the signal of $\mathrm{m} / \mathrm{z}=1553.90$ can be assigned to $\mathrm{TBAK}_{3}\left[\mathrm{PtV}_{9} \mathrm{O}_{28} \mathrm{H}_{3}\right]^{-\cdot}\left(\mathrm{H}_{2} \mathrm{O}\right)_{5}$ species, respectively. (c) When the molecular catalyst was re-oxidized by $\mathrm{Br}_{2}$ in above solution, the signals of $\mathrm{m} / \mathrm{z}=1553.90$ and $\mathrm{m} / \mathrm{z}=1589.92$ can be assigned to $\left\{\mathrm{TBAH}_{2}\left[\mathrm{PtV}_{9} \mathrm{O}_{28} \mathrm{H}_{2}\right]^{2-\cdot}\left(\mathrm{CH}_{3} \mathrm{CN}\right)_{5}\right\}_{2},(\mathrm{TBA})_{2} \mathrm{H}_{2}\left[\mathrm{PtV}_{9} \mathrm{O}_{28} \mathrm{H}_{2}\right]^{-}$, respectively. The above experiments demonstrate that $\left\{\mathrm{PtV}_{9}\right\}$ compound behaves as a reversible redox-active and stable catalyst. 


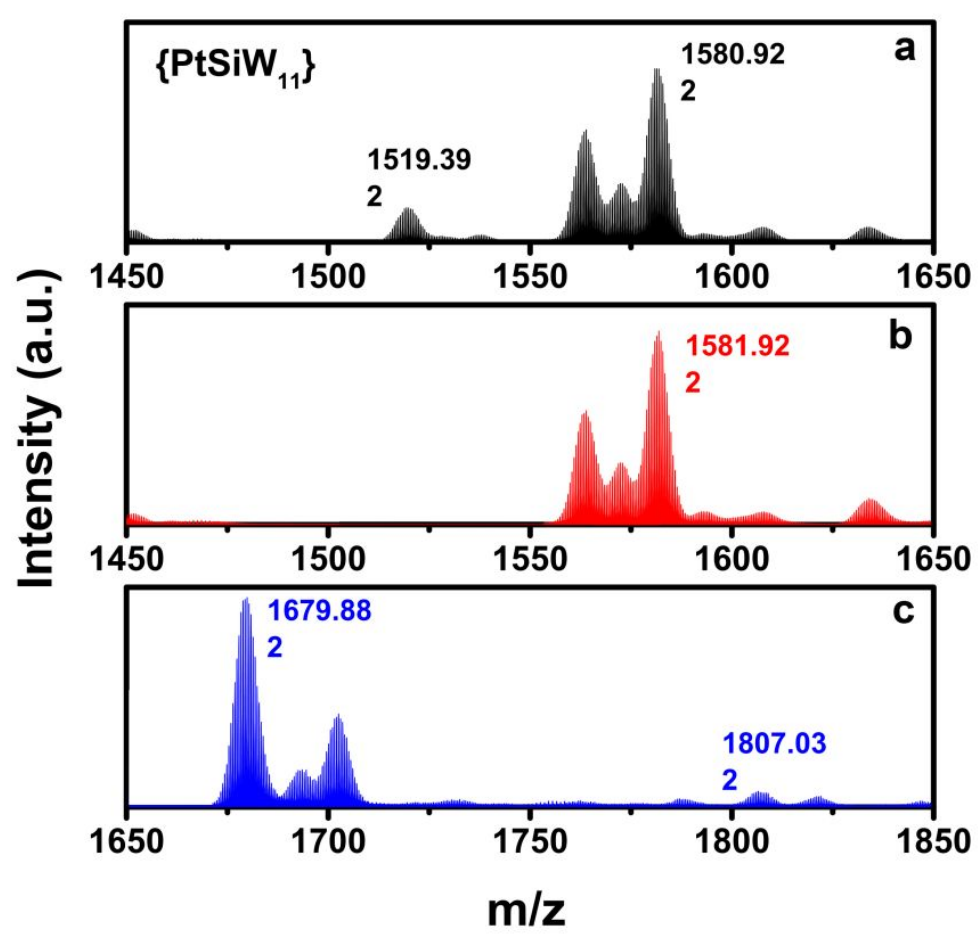

Figure S8. The electrospray-ionization mass spectra (EIS) of $\left\{\mathrm{PtSiW}_{11}\right\}$ compound before and after HER in $0.5 \mathrm{M} \mathrm{H}_{2} \mathrm{SO}_{4}$ aqueous solution as well as its re-oxidized species by $\mathrm{Br}_{2}$. The test samples are prepared by precipitating the polyoxoanion with tetrabutylammonium (TBA) bromide and dissolved in $\mathrm{CH}_{3} \mathrm{CN}$. (a) Before HER, the signals of $\mathrm{m} / \mathrm{z}=1519.39$ and $\mathrm{m} / \mathrm{z}=1580.92$ can be assigned to $\mathrm{H}_{2}\left[\mathrm{PtSiW}_{11} \mathrm{O}_{40} \mathrm{H}_{2}\right]^{2-.} \quad\left(\mathrm{H}_{2} \mathrm{O}\right)_{6}\left(\mathrm{CH}_{3} \mathrm{CN}\right)$ and $\mathrm{H}_{2}\left[\mathrm{PtSiW}_{11} \mathrm{O}_{40} \mathrm{H}_{2}\right]^{2-.} \quad\left(\mathrm{H}_{2} \mathrm{O}\right)_{6}\left(\mathrm{CH}_{3} \mathrm{CN}\right)_{4}$ species. (b) After $\left\{\mathrm{PtSiW}_{11}\right\}$ catalyst has undergone HER for 10 cycles in $0.5 \mathrm{M} \mathrm{H}_{2} \mathrm{SO}_{4}$ aqueous solution, the signal of $\mathrm{m} / \mathrm{z}=1581.92$ can be assigned to $\mathrm{H}_{2}\left[\mathrm{PtSiW}_{11} \mathrm{O}_{40} \mathrm{H}_{4}\right]$ 2-. $\left(\mathrm{H}_{2} \mathrm{O}\right)_{6}\left(\mathrm{CH}_{3} \mathrm{CN}\right)_{4}$ species, respectively. (c) When the molecular catalyst was reoxidized by $\mathrm{Br}_{2}$ in above solution, the signals of $\mathrm{m} / \mathrm{z}=1679.88$ and $\mathrm{m} / \mathrm{z}=1807.03$ can be assigned to $\mathrm{H}_{2}\left[\mathrm{PtSiW}_{11} \mathrm{O}_{40} \mathrm{H}_{4}\right]^{2-} \quad\left(\mathrm{H}_{2} \mathrm{O}\right)_{17}\left(\mathrm{CH}_{3} \mathrm{CN}\right)_{4} \quad$ and $\mathrm{H}_{2}\left[\mathrm{PtSiW}_{11} \mathrm{O}_{40} \mathrm{H}_{4}\right]^{2-} \quad\left(\mathrm{H}_{2} \mathrm{O}\right)_{22}\left(\mathrm{CH}_{3} \mathrm{CN}\right)_{8}$, respectively. The above experiments demonstrate that $\left\{\mathrm{PtSiW}_{11}\right\}$ compound behaves as a reversible redox-active and stable catalyst. 

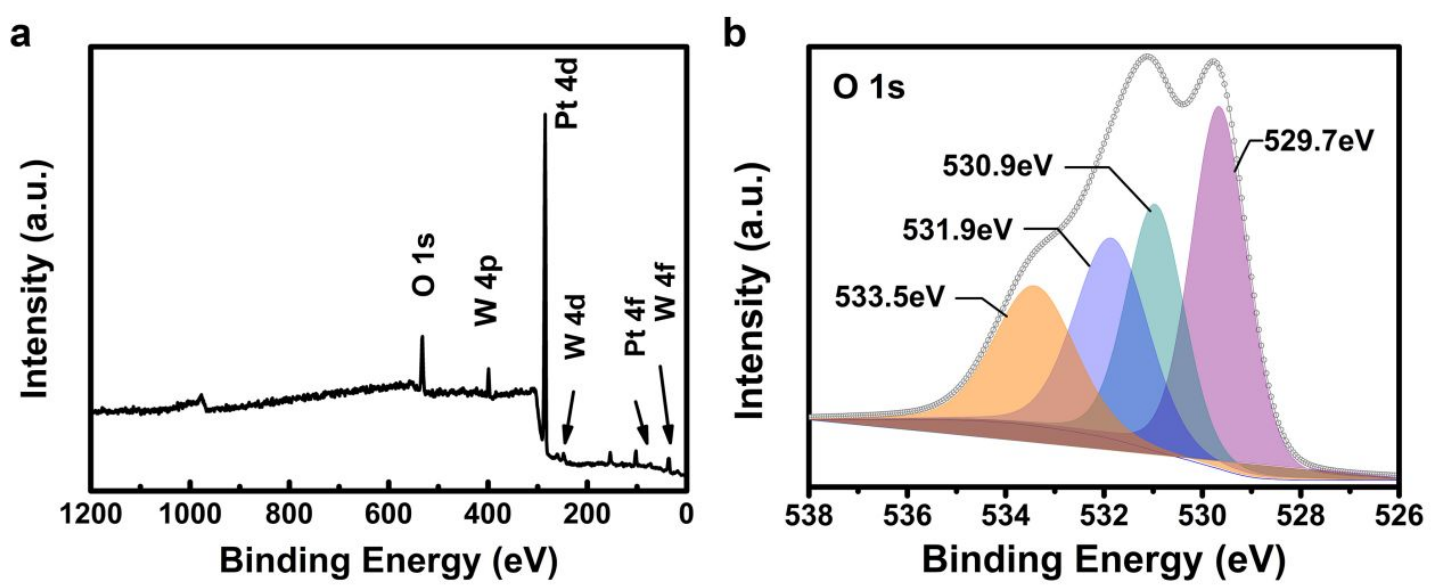

Figure S9. (a) Full-scan XPS spectrum of $\left\{\mathrm{PtW}_{6}\right\}$, indicating that the existence of oxygen, tungsten and platinum elements. (b) High-resolution XPS spectra of $\mathrm{O}$ for $\left\{\mathrm{PtW}_{6}\right\}$. The peaks at $529.7 \mathrm{eV}$ and $530.9 \mathrm{eV}$ belong to $\mathrm{W}=\mathrm{O}$ and $\mathrm{W}-\mathrm{O}-\mathrm{W}$ bonds, respectively. The peaks belong to $531.9 \mathrm{eV}$ and $533.5 \mathrm{eV}$ can be attributed to the protonation of the $\mathrm{Pt}-\mathrm{OH}-\mathrm{W}$ bond and crystalline $\mathrm{H}_{2} \mathrm{O}$, respectively. 

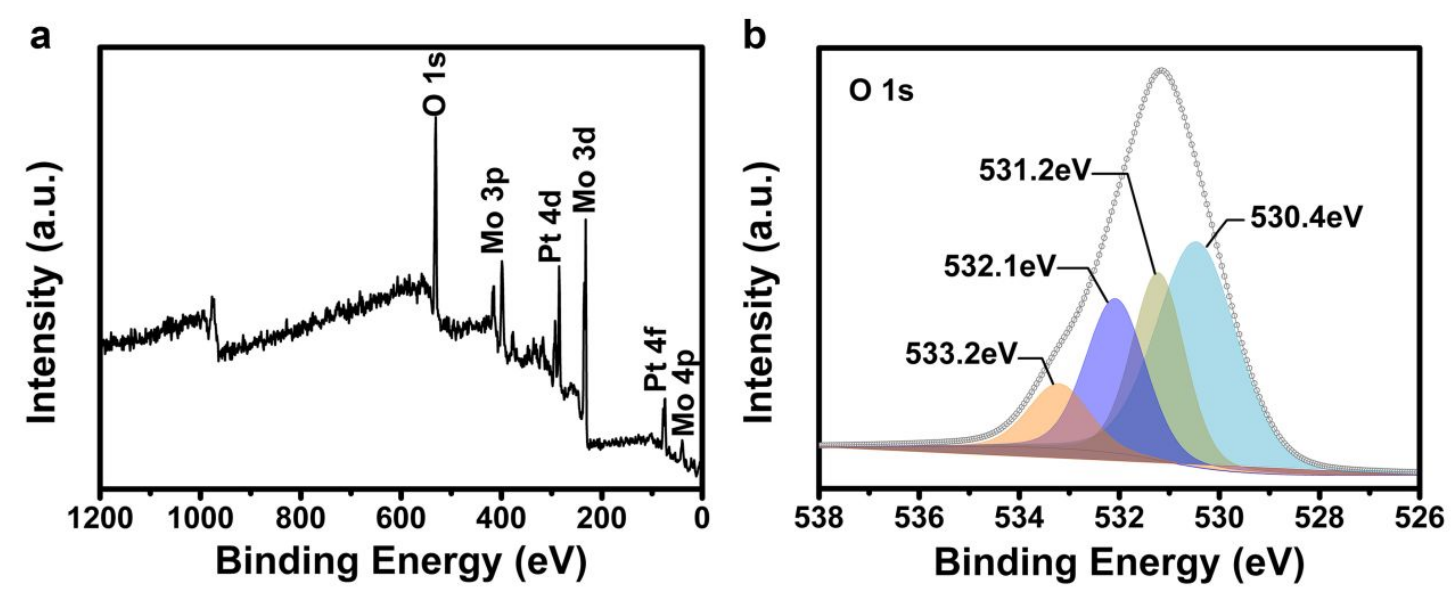

Figure S10. (a) Full-scan XPS spectrum of $\left\{\mathrm{PtMo}_{6}\right\}$, indicating that the existence of oxygen, molybdenum and platinum elements. (b) High-resolution XPS spectra of $\mathrm{O}$ for $\left\{\mathrm{PtMo}_{6}\right\}$. The peaks at $530.4 \mathrm{eV}$ and $531.2 \mathrm{eV}$ belong to $\mathrm{Mo}=\mathrm{O}$ and Mo-O-Mo bonds, respectively. The peaks belong to $532.1 \mathrm{eV}$ and $533.2 \mathrm{eV}$ can be attributed to the protonation of the Pt-OH-Mo bond and crystalline $\mathrm{H}_{2} \mathrm{O}$, respectively. 

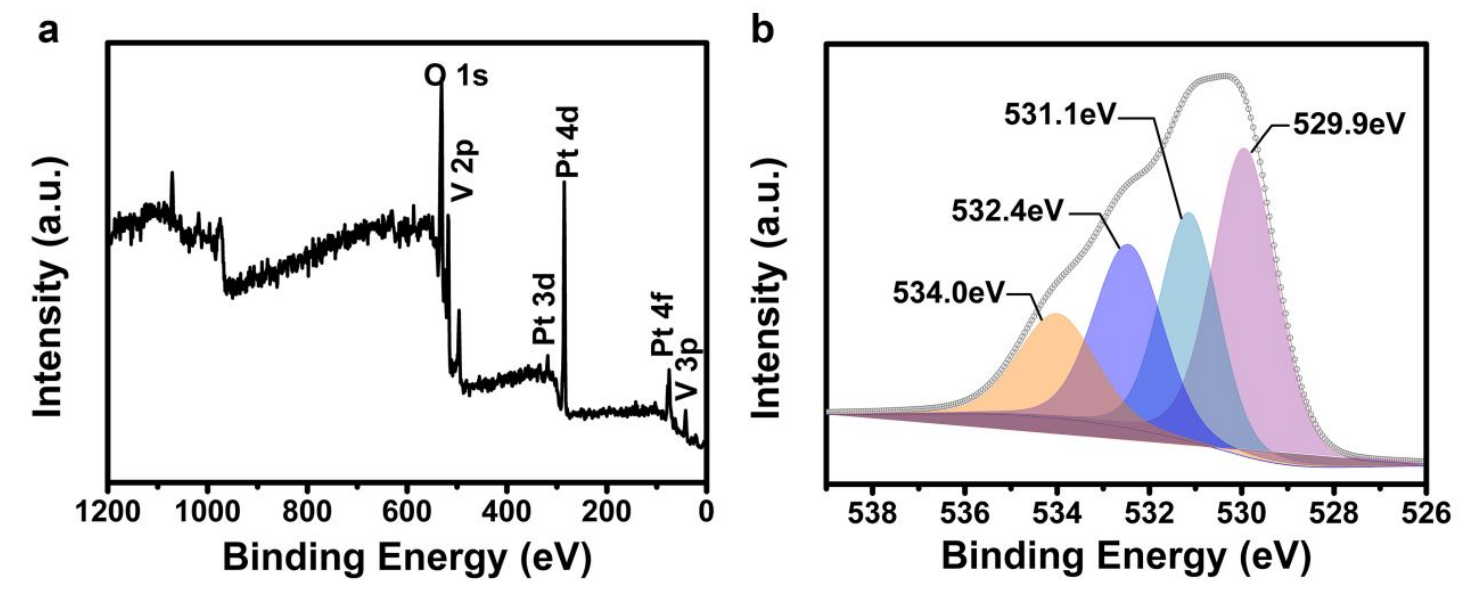

Figure S11. (a) Full-scan XPS spectrum of $\left\{\mathrm{PtV}_{9}\right\}$, indicating that the existence of oxygen, vanadium and platinum elements. (b) High-resolution XPS spectra of $\mathrm{O}$ for $\left\{\mathrm{PtV}_{9}\right\}$. The peaks at $529.9 \mathrm{eV}$ and $531.1 \mathrm{eV}$ belong to $\mathrm{V}=\mathrm{O}$ and $\mathrm{V}-\mathrm{O}-\mathrm{V}$ bonds, respectively. The peaks belong to $532.4 \mathrm{eV}$ and $534.0 \mathrm{eV}$ can be attributed to the protonation of the Pt-O-V bond and crystalline $\mathrm{H}_{2} \mathrm{O}$, respectively. 
a

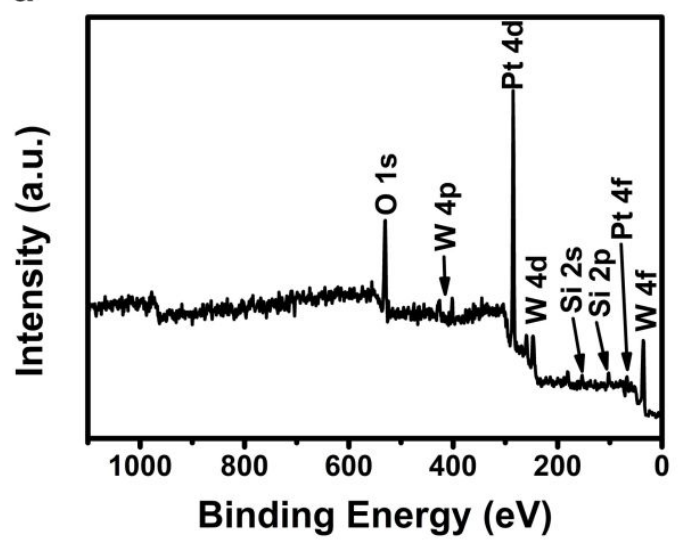

b

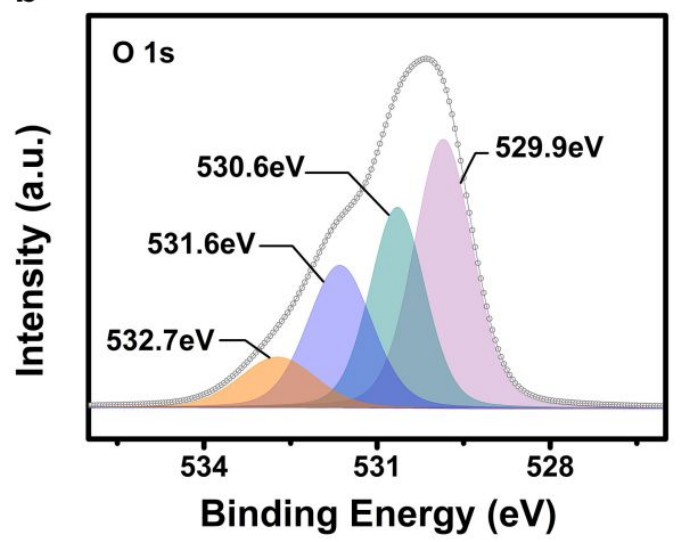

Figure S12. (a) Full-scan XPS spectrum of $\left\{\mathrm{PtSiW}_{11}\right\}$, indicating that the existence of oxygen, tungsten and platinum elements. (b) High-resolution XPS spectra of $\mathrm{O}$ for $\left\{\mathrm{PtSiW}_{11}\right\}$. The peaks at $529.9 \mathrm{eV}$ and $530.6 \mathrm{eV}$ belong to $\mathrm{W}=\mathrm{O}$ and $\mathrm{W}-\mathrm{O}-\mathrm{W}$ bonds, respectively. The peaks belong to $531.6 \mathrm{eV}$ and $532.7 \mathrm{eV}$ can be attributed to the protonation of the Pt-O-W bond and crystalline $\mathrm{H}_{2} \mathrm{O}$, respectively. 


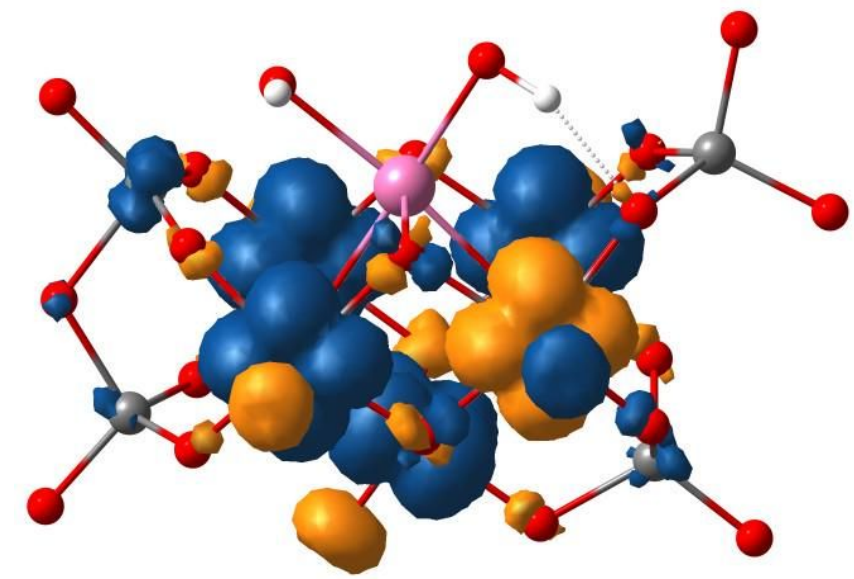

Figure S13. The spin density representation for the five reduced state of species $\left[\mathrm{H}_{2} \mathrm{Pt}^{\mathrm{IV}} \mathrm{V}_{9} \mathrm{O}_{28}\right]^{5-}$ The five reduced electrons are delocalized over five $\mathrm{V}$ sites. 

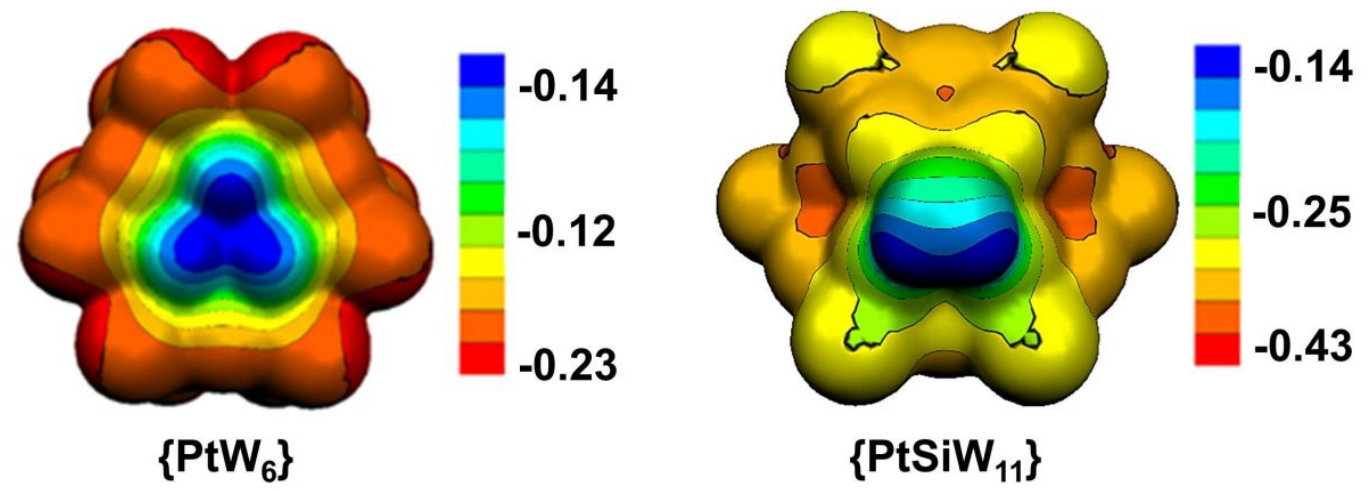

Figure S14. MEP distribution for $\left\{\mathrm{PtW}_{6}\right\}$ and $\left\{\mathrm{PtSiW}_{11}\right\}$ : the red and blue or green identify more and less nucleophilic regions for $\mathrm{H}^{+}$. 


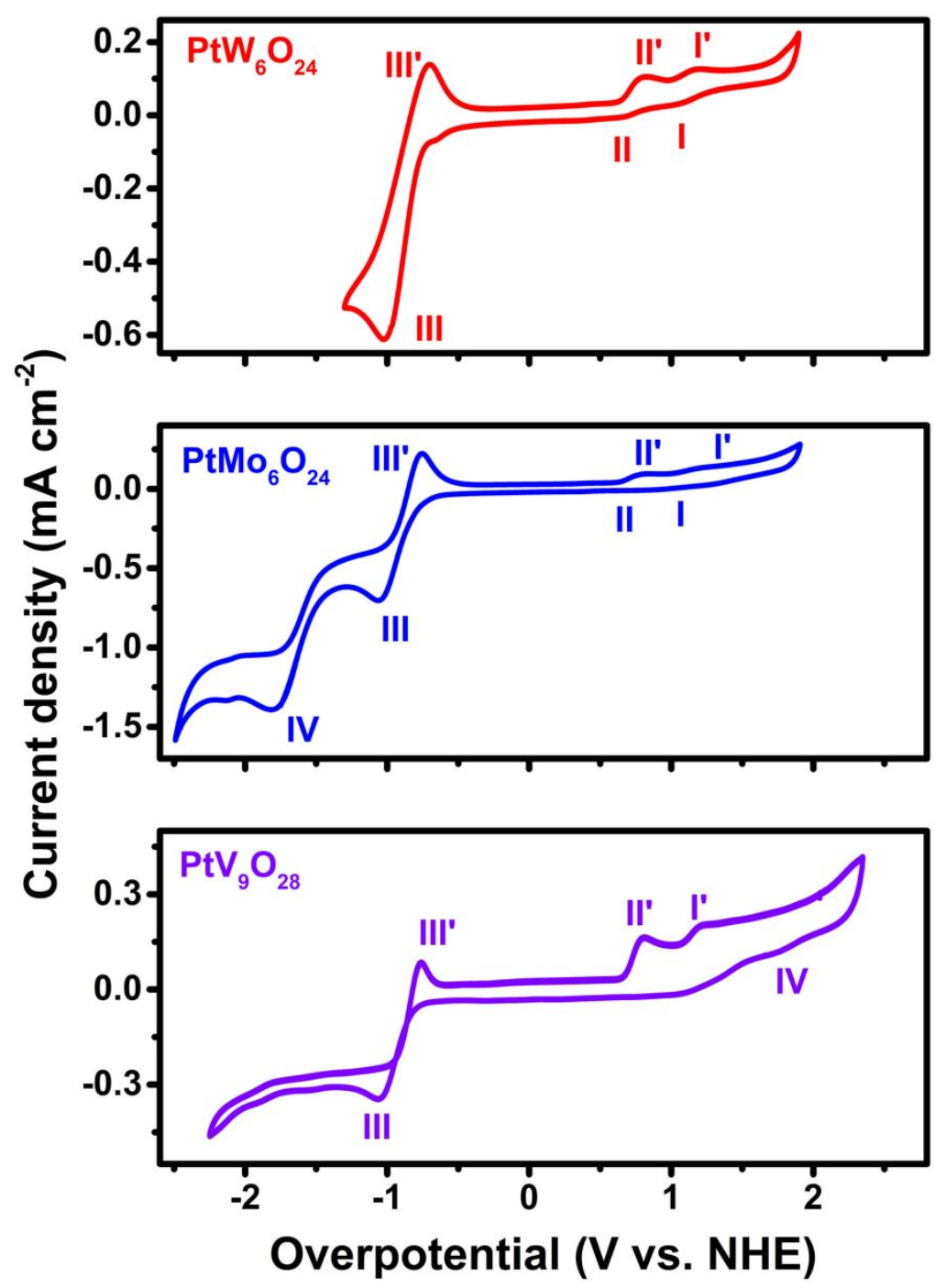

Figure S15. The cycle voltammetry of $\left\{\mathrm{PtW}_{6}\right\}$ (red), $\left\{\mathrm{PtMo}_{6}\right\}$ (blue), and $\left\{\mathrm{PtV}_{9}\right\}$ (violet) in $\mathrm{N}_{2}$-saturated acetonitrile at the overpotential of $40 \mathrm{mV}$. the reduction peaks at $1.02 \mathrm{~V}$ and $0.68 \mathrm{~V}$ are attributed to the 1-electron and 1-electron reduction of $\mathrm{Pt}$, and the reduction peak at $-1.02 \mathrm{~V}$ is attributed to $\mathrm{W}$ on the cyclic voltammetry curve of $\left\{\mathrm{PtW}_{6}\right\}$. In the $\mathrm{CV}$ of $\left\{\mathrm{PtMo}_{6}\right\}$, there are reduction peaks at $0.97 \mathrm{~V}$ and $0.49 \mathrm{~V}$, which are attributed to the 1-electron and 1-electron reduction peaks of $\mathrm{Pt}$, and the reduction peak at $-1.05 \mathrm{~V}$ and $-1.81 \mathrm{~V}$ is ascribed to Mo. It is noting that the reduction peak of $\mathrm{V}$ is obtained at $1.72 \mathrm{~V}$ on the cyclic voltammetry curve of $\left\{\mathrm{PtV}_{9}\right\}$, which is consistent with the literature. Unfortunately, the reduction peak of $\mathrm{Pt}$ is not observed. The reduction peak at $-1.06 \mathrm{~V}$ is accredit to $\mathrm{V}$. It shows clearly that Pt obtained electrons primarily during the electrochemistry process, and then the HER occurs with $\left\{\mathrm{PtW}_{6}\right\}$ and $\left\{\mathrm{PtMo}_{6}\right\}$. However, $\mathrm{V}$ obtained electrons before $\mathrm{Pt}$ in the $\mathrm{CV}$ of $\left\{\mathrm{PtV}_{9}\right\}$. This obvious difference implies that the different support has a significant impact on the electron transfer process and may affect the effective potential of the active center during the hydrogen evolution process.

According to the Butler-Volmer equation:

$$
i=n \mathrm{~F} A \mathrm{~K}^{0}\left[C_{O}(0, t) e^{-\alpha f\left(E-E 0^{\prime}\right)}-C_{R}(0, t) e^{(1-\alpha f)\left(E-E 0^{\prime}\right)}\right] \quad(\text { Supplementary Equation 1) }
$$


In order to make a clearer comparison of the electronic behavior of them, only Pt to obtain the electrochemical window is focused. At this time, the product concentration is very low, so supplementary equation 1 can be simplified as:

$$
i=n \mathrm{~F} A k^{0} \operatorname{Co}(0, t) e^{-\alpha f\left(E-E 0^{\prime}\right)} \quad \text { (Supplementary Equation 2) }
$$

It can be obtained by simple mathematical derivation:

$$
E-E^{0^{\prime}}=\frac{n R T A k^{0} C_{0}(0, t)}{2.303 \alpha}-\frac{R T}{2.303 \alpha F} \log (i) \quad(\text { Supplementary Equation } 3)
$$



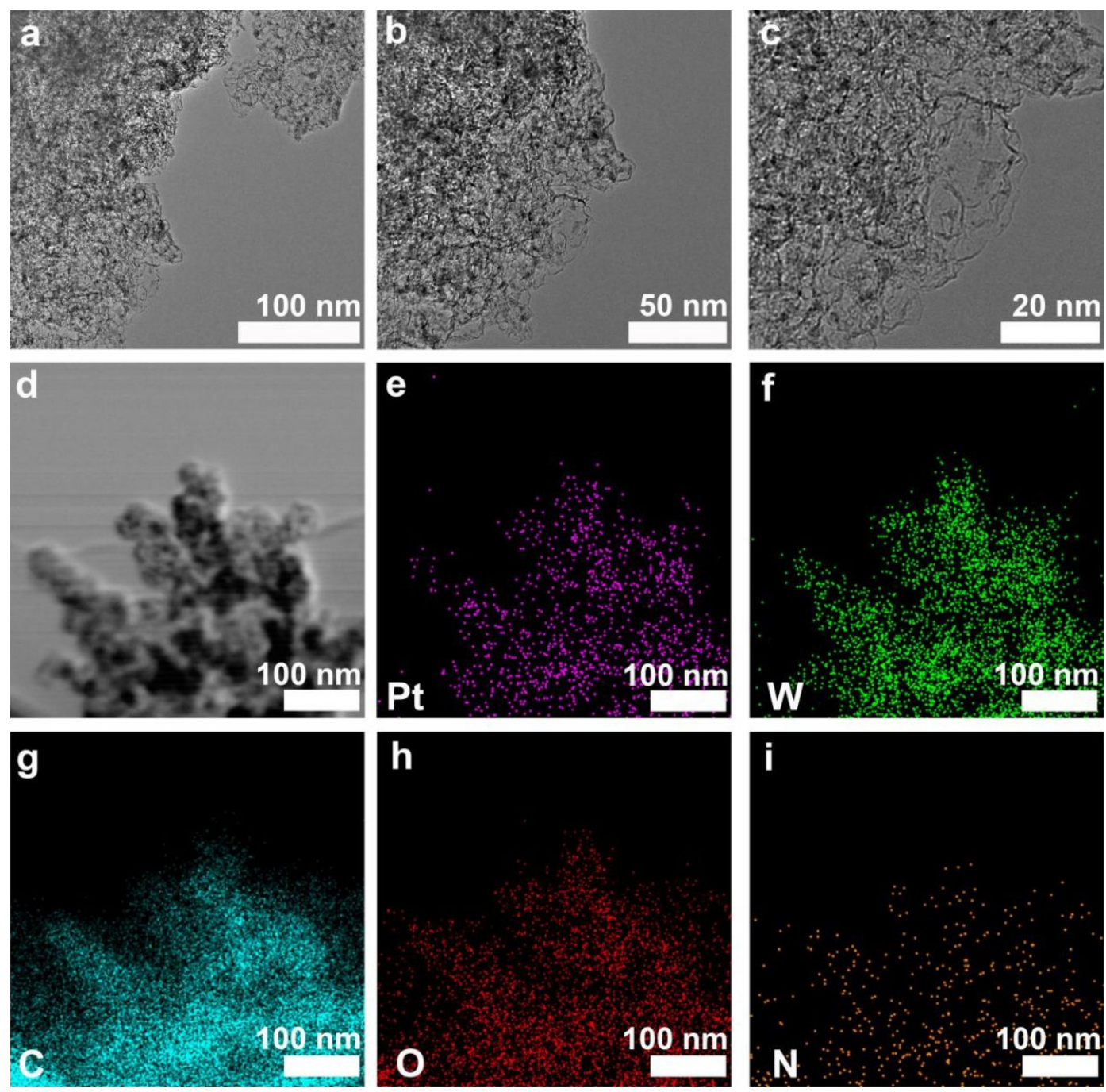

Figure S16. (a-c) TEM of $1 \%\left\{\mathrm{PtW}_{6}\right\} / \mathrm{C}$. (d-i) Element mapping of $1 \%\left\{\mathrm{PtW}_{6}\right\} / \mathrm{C}, \mathrm{Pt}$ (e), W (f), $\mathrm{C}$ (g), $\mathrm{O}$ (h) and $\mathrm{N}$ (i). No obvious particle aggregation was found, indicating that the $\left\{\mathrm{PtW}_{6}\right\}$ molecules were uniformly dispersed on the Ketjen black carbon. 

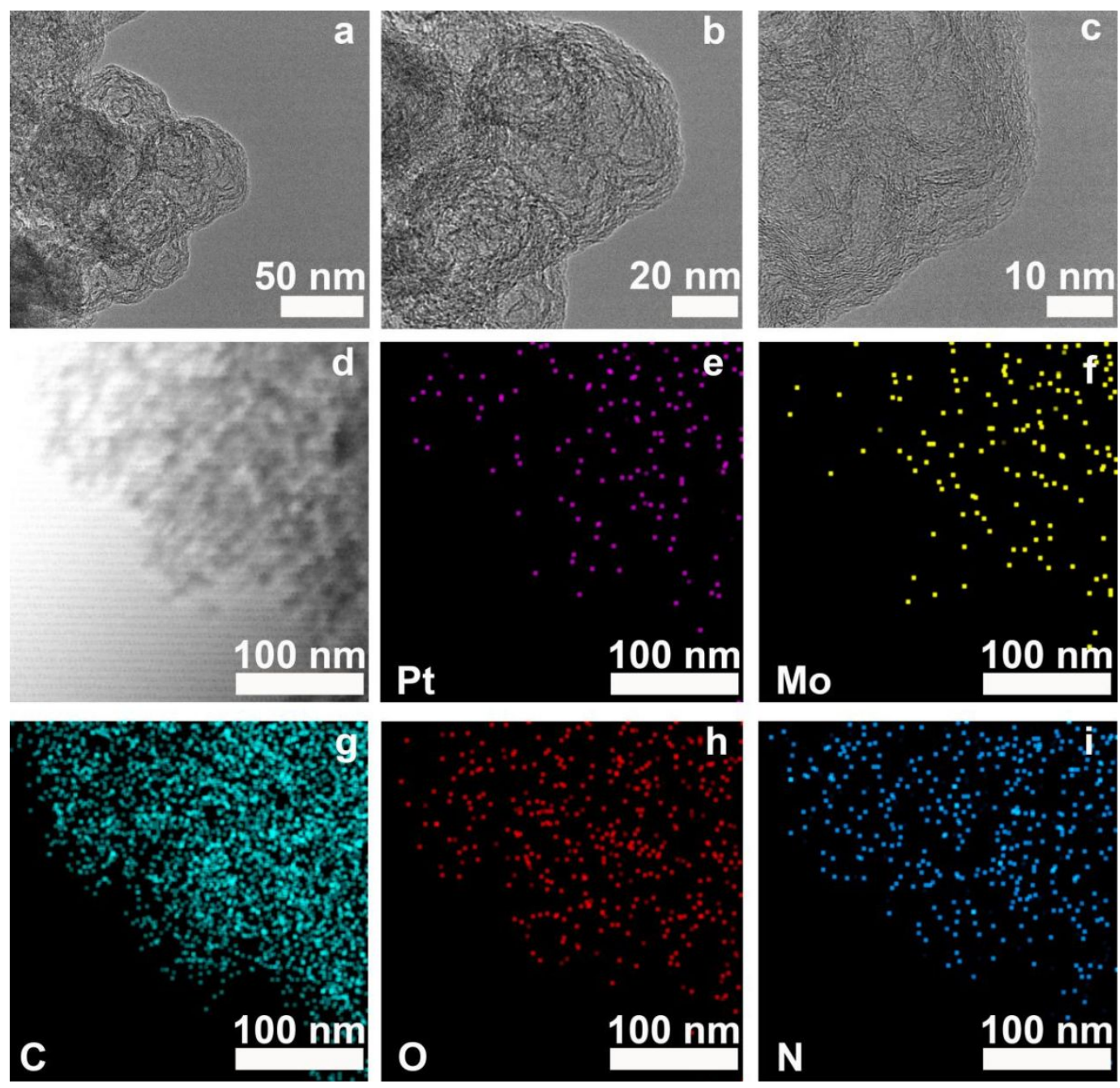

Figure S17. (a-c) TEM of $1 \%\left\{\mathrm{PtMo}_{6}\right\} / \mathrm{C}$. (d-i) Element mapping of $1 \%\left\{\mathrm{PtMo}_{6}\right\} / \mathrm{C}$, Pt (e), Mo (f), C (g), O (h) and $\mathrm{N}$ (i). TEM images show there are not obviously aggregation of particle, meaning that the $\left\{\mathrm{PtMo}_{6}\right\}$ molecules were uniformly dispersed on the Ketjen black carbon. 

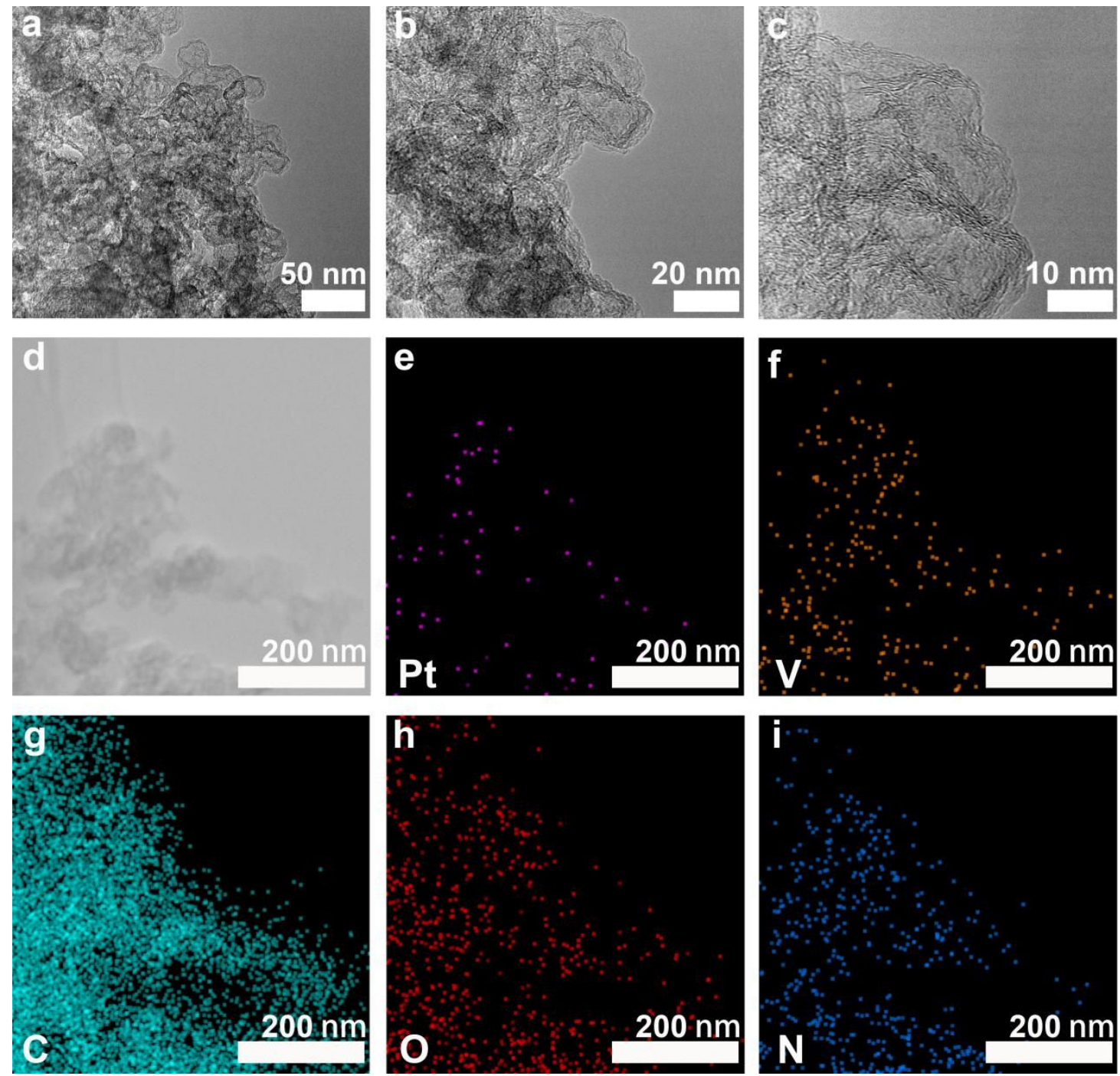

Figure S18. (a-c) TEM of $1 \%\left\{\mathrm{PtV}_{9}\right\} / \mathrm{C}$. (d-i) Element mapping of $1 \%\left\{\mathrm{PtV}_{9}\right\} / \mathrm{C}, \mathrm{Pt}$ (e), V (f), C (g), O (h) and $\mathrm{N}$ (i). TEM images show there are not obviously aggregation of particle, meaning that the $\left\{\mathrm{PtV}_{9}\right\}$ molecules were uniformly dispersed on the Ketjen black carbon. 


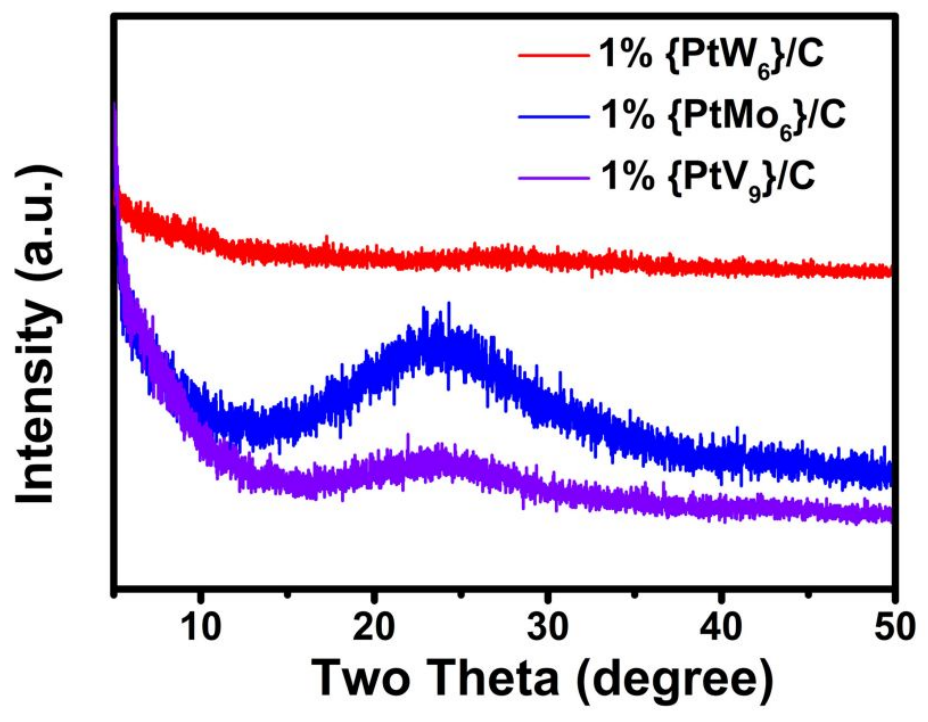

Figure S19. The broad peak at 25 degree can be attributed to Ketjen black carbon. There are no peaks on $\left\{\mathrm{PtW}_{6}\right\} / \mathrm{C},\left\{\mathrm{PtMo}_{6}\right\} / \mathrm{C}$ and $\left\{\mathrm{PtV}_{9}\right\} / \mathrm{C}$ implies that the sizes of $\left\{\mathrm{PtW}_{6}\right\},\left\{\mathrm{PtMo}_{6}\right\}$ and $\left\{\mathrm{PtV}_{9}\right\}$ species are below the detection limit, possibly in the monodisperse regime. 


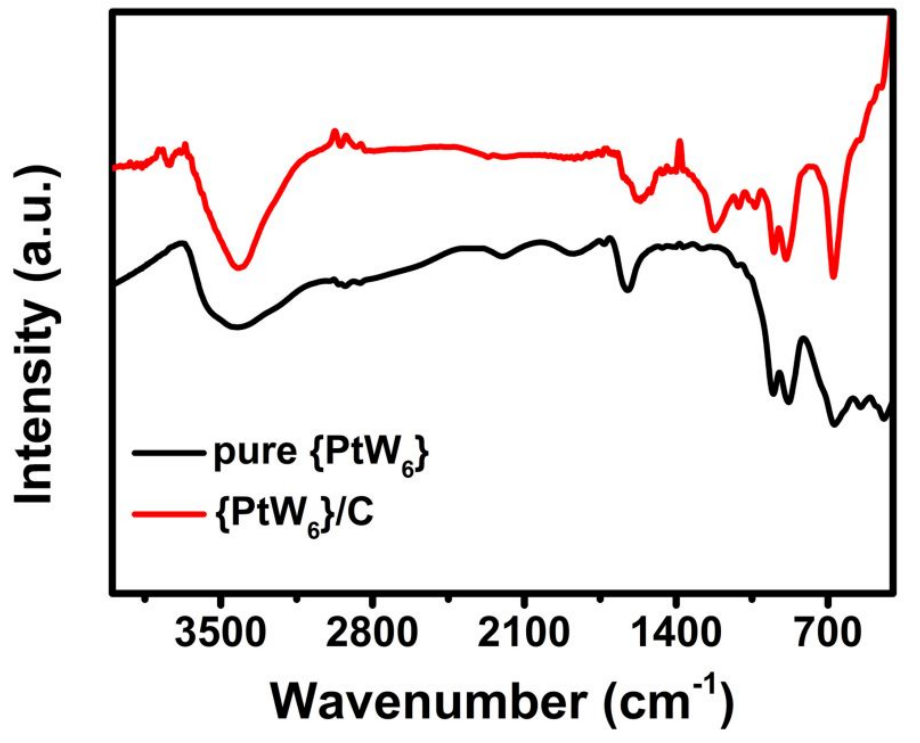

Figure S20. Infrared Spectroscopy (IR) of pure $\left\{\mathrm{PtW}_{6}\right\}$ and $\left\{\mathrm{PtW}_{6}\right\} / \mathrm{C}$. The IR of pure $\left\{\mathrm{PtW}_{6}\right\}$ is similar with that of $\left\{\mathrm{PtW}_{6}\right\} / \mathrm{C}$, which demonstrates that $\left\{\mathrm{PtW}_{6}\right\} / \mathrm{C}$ remain its structure before and after loading on carbon. 


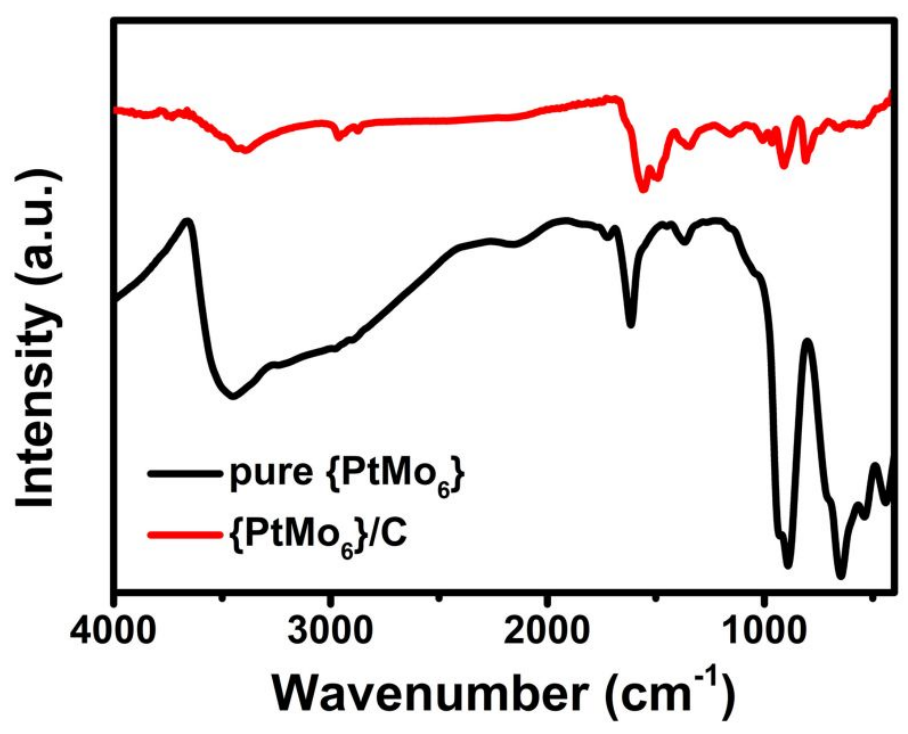

Figure S21. The IR curves of pure $\left\{\mathrm{PtMo}_{6}\right\}$ and $\left\{\mathrm{PtMo}_{6}\right\} / \mathrm{C}$, which means the structure of $\left\{\mathrm{PtMo}_{6}\right\} / \mathrm{C}$ is not destroyed during the materialization process. 


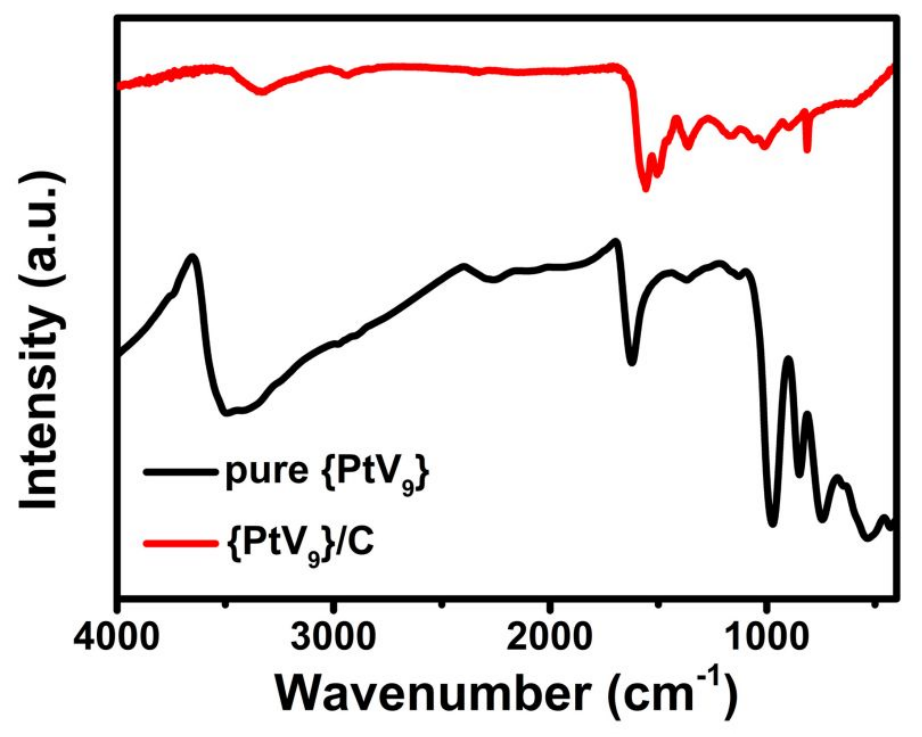

Figure S22. The IR curves of pure $\left\{\mathrm{PtV}_{9}\right\}$ and $\left\{\mathrm{PtV}_{9}\right\} / \mathrm{C}$ which means the structure of $\left\{\mathrm{PtV}_{9}\right\} / \mathrm{C}$ remain well during the materialization process. 

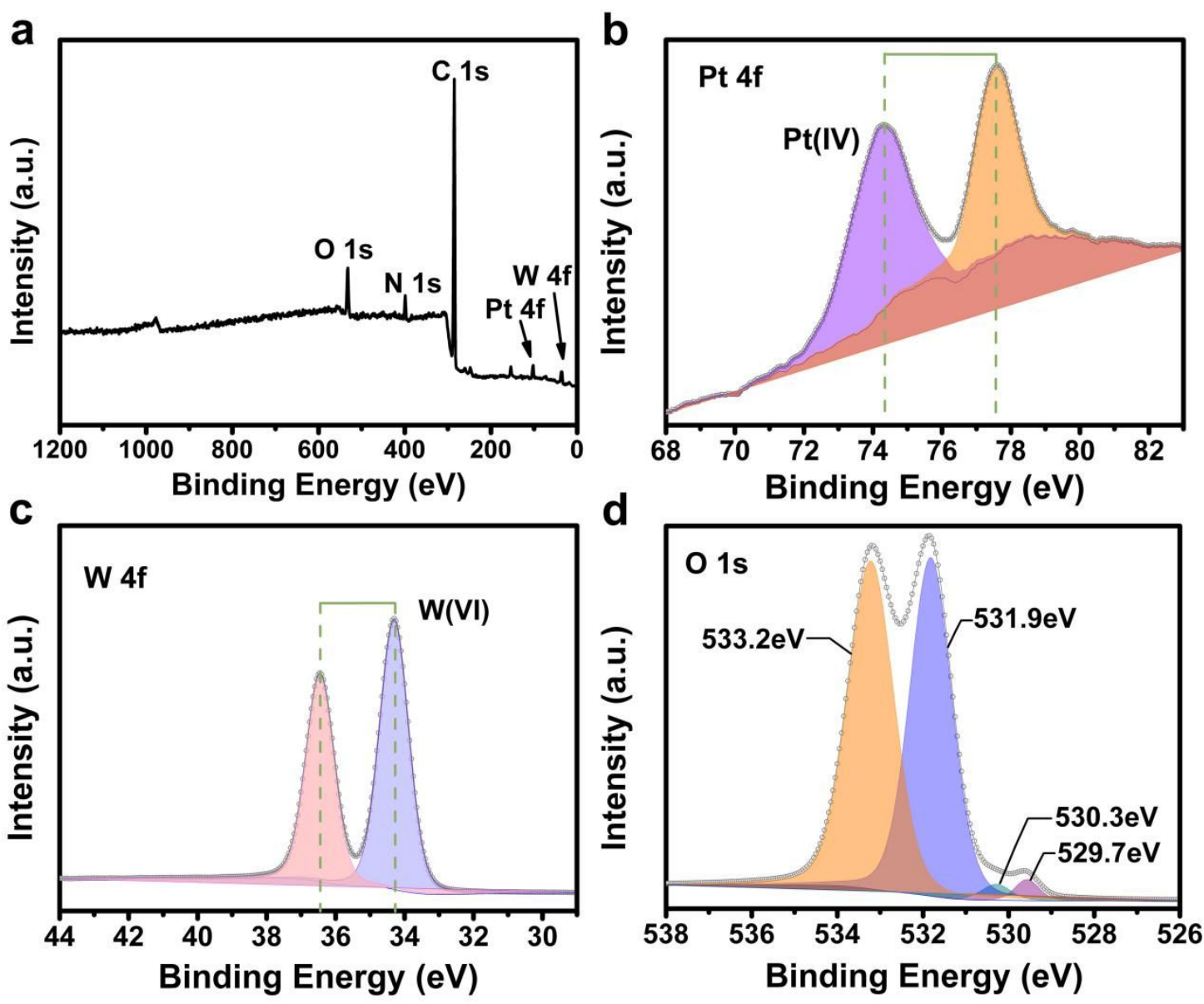

Figure S23. (a) The full XPS spectra for $\left\{\mathrm{PtW}_{6}\right\} / \mathrm{C}$. ((b, c, d) High-resolution XPS spectra of $\mathrm{Pt}, \mathrm{W}$ and $\mathrm{O}$ for $\left\{\mathrm{PtW}_{6}\right\} / \mathrm{C}$.

Figure S23a reveals the full XPS spectrum of $\left\{\mathrm{PtW}_{6}\right\} / \mathrm{C}$, which verifies the presence of $\mathrm{Pt}, \mathrm{W}, \mathrm{O}$ and $\mathrm{C}$ elements. The high resolution XPS spectra of Pt in Figure S23b, the Pt $4 \mathrm{f}_{7 / 2}$ and $\mathrm{Pt} 4 \mathrm{f}_{5 / 2}$ located at 74.3 and $77.7 \mathrm{eV}$, respectively, which are consistent with the presence of $\mathrm{Pt}(\mathrm{IV})$ as reported in the literatures. It is notably that there are not existence of peak at 71.4 and $74.7 \mathrm{eV}$, implying the absence of metallic Pt. The W XPS spectra with two peaks at $34.4 \mathrm{eV}$ and $36.6 \mathrm{eV}$ assigned to $4 \mathrm{f}_{7 / 2}$ and $4 \mathrm{f}_{5 / 2}$ of $\mathrm{W}(\mathrm{VI})$ (Figure $\mathrm{S} 23 \mathrm{c})$. The XPS spectra of O 1s is shown in Figure S23d, the peak at $529.6 \mathrm{eV}$ can be attributed to $\mathrm{W}=\mathrm{O}$. The signal at $530.5 \mathrm{eV}$ is related to the $\mathrm{W}-\mathrm{O}-\mathrm{W}$ bond. The peak at $531.9 \mathrm{eV}$ is assigned to oxygen present on the surface of carbon, which may come from oxygen adsorbed on carbon, and covers the peak of $\mathrm{Pt}-\mathrm{O}$ bond. The peak at $533.1 \mathrm{eV}$ is distribute to the presence of the hydroxyl $(\mathrm{O}-\mathrm{H})$, which may be attributed to the presence of hydrogen protons attached to oxygen atoms and the crystal $\mathrm{H}_{2} \mathrm{O}$ adsorbed throughout the $\left\{\mathrm{PtW}_{6}\right\} / \mathrm{C}$ molecule. All little shifts of peaks are ascribed to the interaction of $\left\{\mathrm{PtW}_{6}\right\} / \mathrm{C}$ with carbon. 

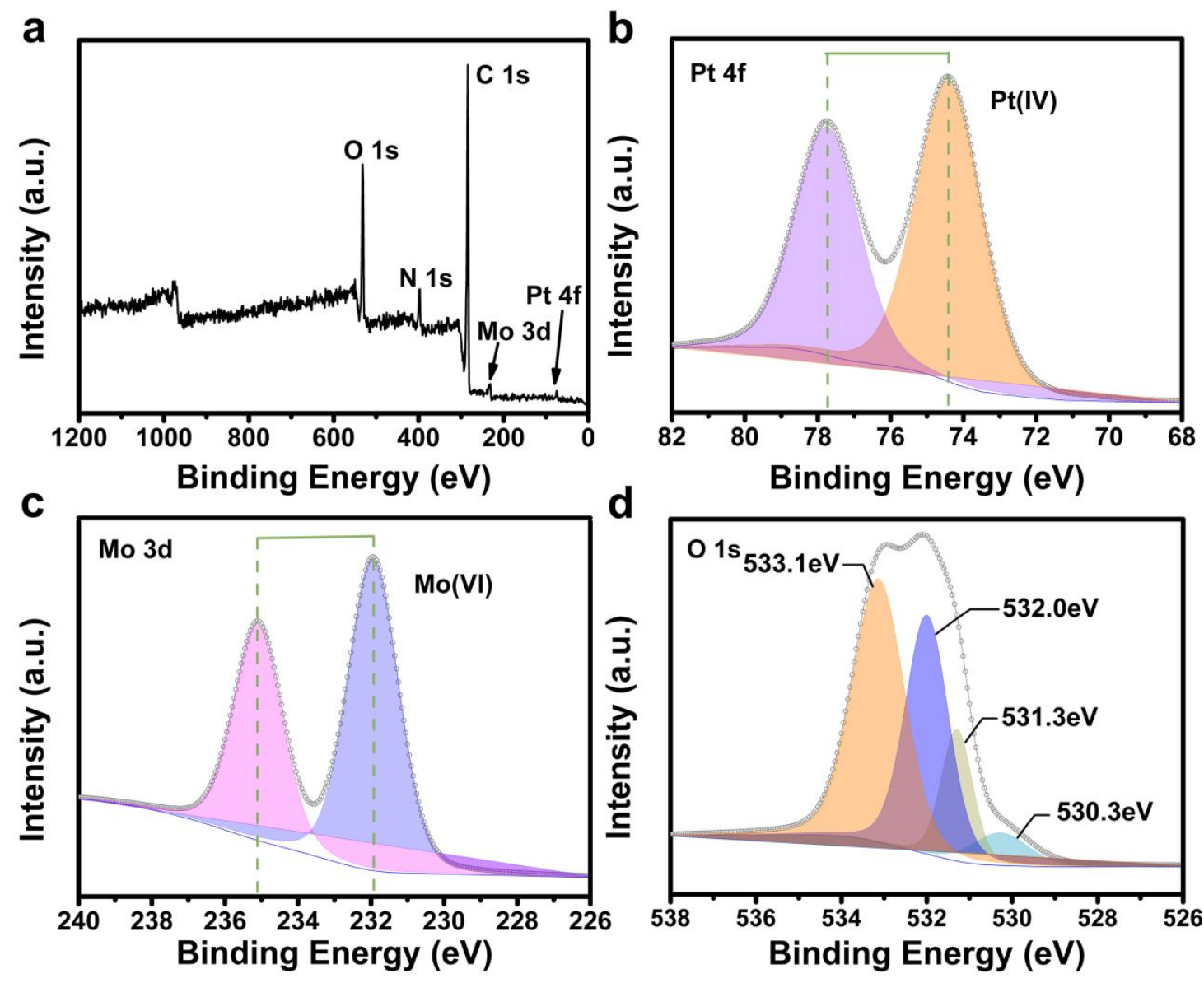

Figure S24. (a) The full XPS spectra for $\left\{\mathrm{PtMo}_{6}\right\} / \mathrm{C}$. ((b, c, d) High-resolution XPS spectra of $\mathrm{Pt}, \mathrm{Mo}$ and $\mathrm{O}$ for $\left\{\mathrm{PtMo}_{6}\right\} / \mathrm{C}$.

Figure S24a reveals the full XPS spectrum of $\left\{\mathrm{PtMo}_{6}\right\} / \mathrm{C}$, which verifies the presence of Pt, Mo, O and C elements. The high resolution XPS spectra of Pt in Figure S24b, the $\mathrm{Pt} 4 \mathrm{f}_{7 / 2}$ and $\mathrm{Pt} 4 \mathrm{f}_{5 / 2}$ located at 74.4 and $77.7 \mathrm{eV}$, respectively, which are consistent with the presence of $\mathrm{Pt}(\mathrm{IV})$ as reported in the literatures. The Mo XPS spectra with two peaks at $231.9 \mathrm{eV}$ and $235.1 \mathrm{eV}$ assigned to $3 \mathrm{~d}_{5 / 2}$ and $3 \mathrm{~d}_{3 / 2}$ of Mo(VI) (Figure S24c). The XPS spectra of $\mathrm{O} 1 \mathrm{~s}$ is shown in Figure $\mathrm{S} 24 \mathrm{~d}$, the peak at $530.3 \mathrm{eV}$ can be attributed to $\mathrm{Mo}=\mathrm{O}$. The signal at $531.3 \mathrm{eV}$ is related to the Mo-O-Mo bond. The peak at $532.0 \mathrm{eV}$ is assigned to oxygen present on the surface of carbon, which may come from oxygen adsorbed on carbon, and covers the peak of Pt-O bond. The peak at $533.1 \mathrm{eV}$ is distribute to the presence of the hydroxyl $(\mathrm{O}-\mathrm{H})$, which may be attributed to the presence of hydrogen protons attached to oxygen atoms and the crystal $\mathrm{H}_{2} \mathrm{O}$ adsorbed throughout the $\left\{\mathrm{PtMo}_{6}\right\} / \mathrm{C}$ molecule. All little shifts of peaks are ascribed to the interaction of $\left\{\mathrm{PtMo}_{6}\right\} / \mathrm{C}$ with carbon. 

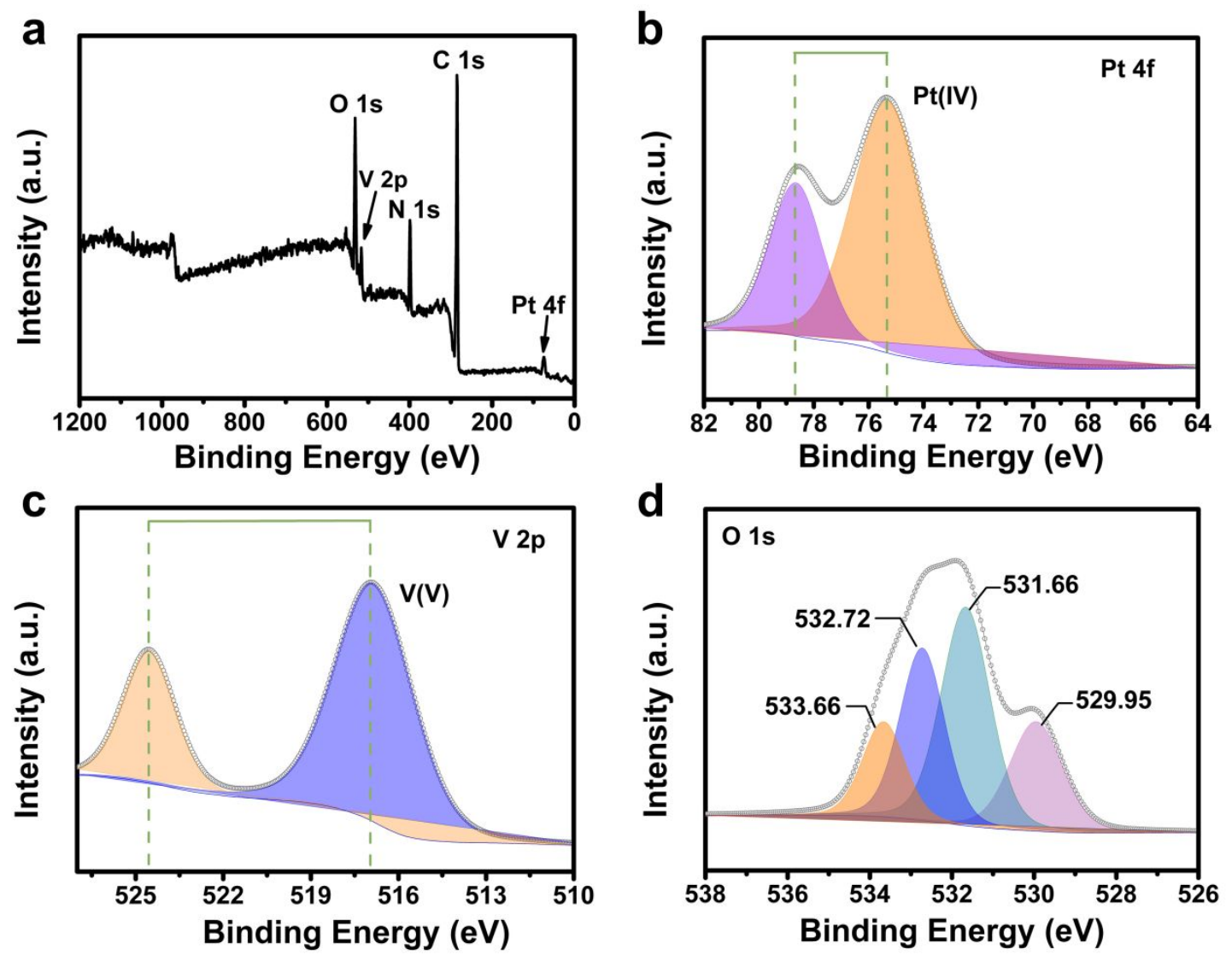

Figure S25. (a) The full XPS spectra for $\left\{\mathrm{PtV}_{9}\right\} / \mathrm{C}$. ((b, c, d) High-resolution XPS spectra of $\mathrm{Pt}, \mathrm{V}$ and $\mathrm{O}$ for $\left\{\mathrm{PtV}_{9}\right\} / \mathrm{C}$.

Figure S24a reveals the full XPS spectrum of $\left\{\mathrm{PtV}_{9}\right\} / \mathrm{C}$, which verifies the presence of $\mathrm{Pt}, \mathrm{Mo}, \mathrm{O}$ and $\mathrm{C}$ elements. The high resolution XPS spectra of Pt in Figure S25b, the $\mathrm{Pt} 4 \mathrm{f}_{7 / 2}$ and $\mathrm{Pt}_{4 / 2} \mathrm{f}_{5 / 2}$ located at 75.3 and $78.6 \mathrm{eV}$, respectively, which are consistent with the presence of $\mathrm{Pt}(\mathrm{IV})$ as reported in the literatures. The Mo XPS spectra with two peaks at $516.8 \mathrm{eV}$ and $524.5 \mathrm{eV}$ assigned to $2 \mathrm{p}_{3 / 2}$ and $2 \mathrm{p}_{1 / 2}$ of V(V) (Figure S25c). The XPS spectra of $\mathrm{O} 1 \mathrm{~s}$ is shown in Figure S25d, the peak at $529.95 \mathrm{eV}$ can be attributed to $\mathrm{V}=\mathrm{O}$. The signal at $531.66 \mathrm{eV}$ is related to the $\mathrm{V}-\mathrm{O}-\mathrm{V}$ bond. The peak at $532.72 \mathrm{eV}$ is assigned to oxygen present on the surface of carbon, which may come from oxygen adsorbed on carbon, and covers the peak of Pt-O bond. The peak at $533.66 \mathrm{eV}$ is distribute to the presence of the hydroxyl $(\mathrm{O}-\mathrm{H})$, which may be attributed to the presence of hydrogen protons attached to oxygen atoms and the crystal $\mathrm{H}_{2} \mathrm{O}$ adsorbed throughout the $\left\{\mathrm{PtV}_{9}\right\} / \mathrm{C}$ molecule. All little shifts of peaks are ascribed to the interaction of $\left\{\mathrm{PtV}_{9}\right\} / \mathrm{C}$ with carbon. 


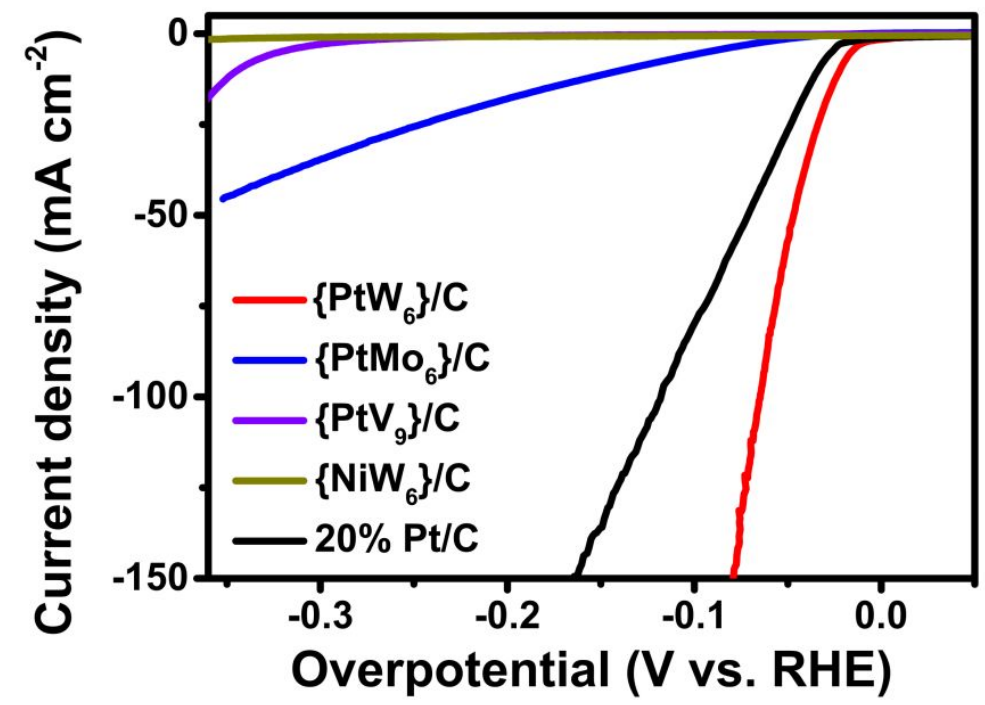

Figure S26. The polarization curves of $\left\{\mathrm{PtW}_{6}\right\} / \mathrm{C},\left\{\mathrm{PtMo}_{6}\right\} / \mathrm{C},\left\{\mathrm{PtV}_{9}\right\} / \mathrm{C},\left\{\mathrm{NiW}_{6}\right\} / \mathrm{C}$ and $20 \% \mathrm{Pt} / \mathrm{C}$ at $10 \mathrm{~mA} \mathrm{~cm}^{-2}$ in $\mathrm{N}_{2}$-saturated $0.5 \mathrm{M} \mathrm{H}_{2} \mathrm{SO}_{4}$. 


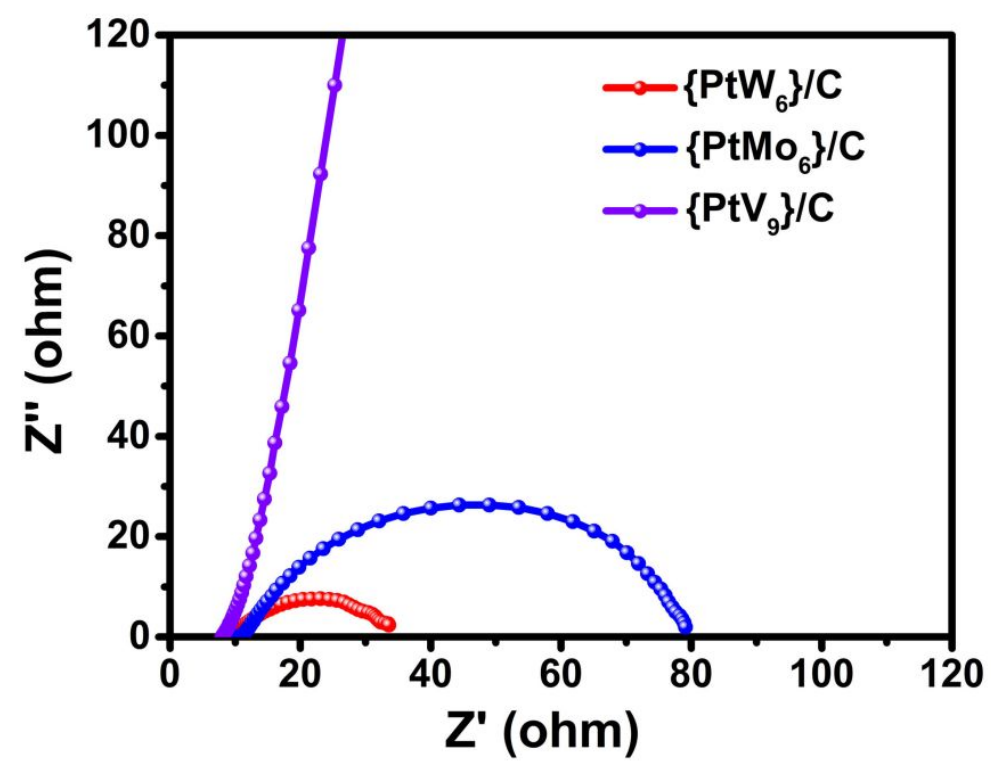

Figure S27. The Electrochemical impedance spectroscopy (EIS) of $\left\{\mathrm{PtW}_{6}\right\} / \mathrm{C}$, $\left\{\mathrm{PtMo}_{6}\right\} / \mathrm{C}$, and $\left\{\mathrm{PtV}_{9}\right\} / \mathrm{C}$ at overpotential of $40 \mathrm{mV}$. 


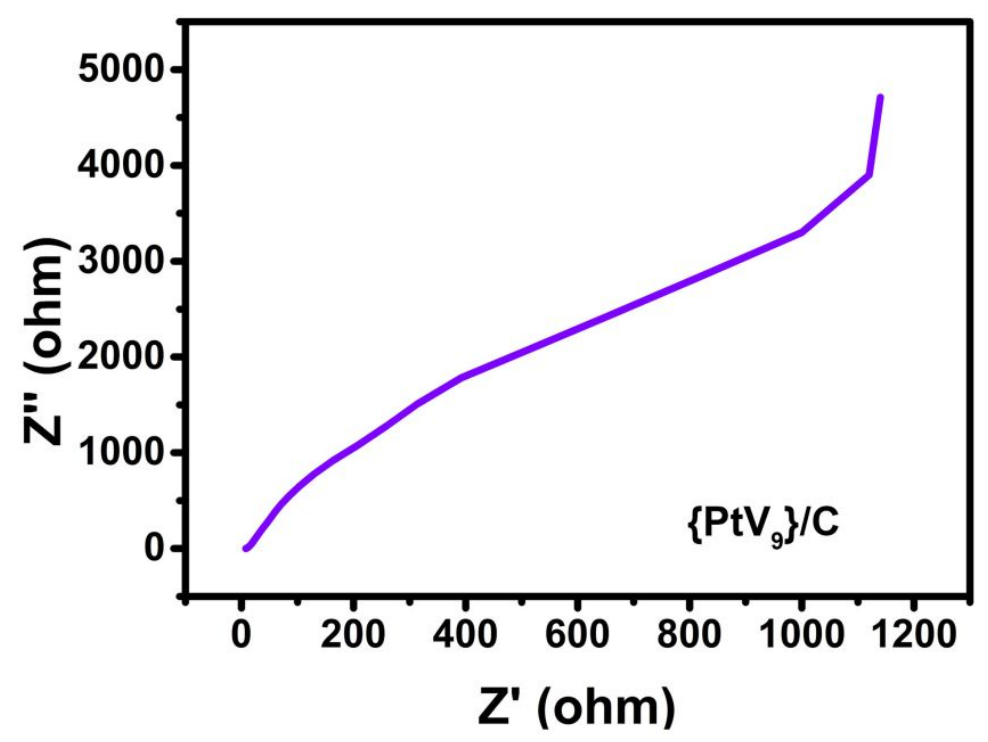

Figure S28. The complete data of electrochemical impedance spectroscopy (EIS) of $\left\{\mathrm{PtV}_{9}\right\} / \mathrm{C}$ at overpotential of $40 \mathrm{mV}$. 


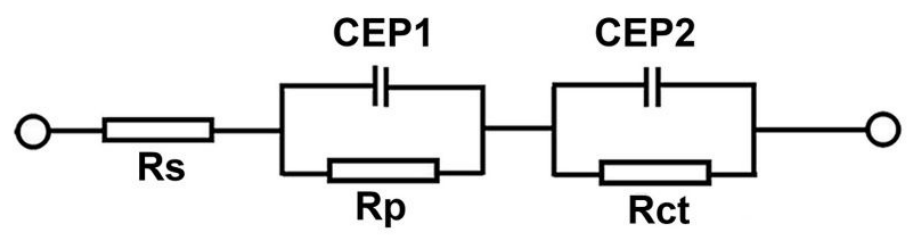

Figure S29. Two-time-constant model equivalent circuit used for data fitting of EIS spectra (Rs represents the overall series resistance, CPE1 and CPE2 represent the constant phase element and resistance related to surface porosity Rp, and Rct represents the charge transfer resistance related to HER process). 


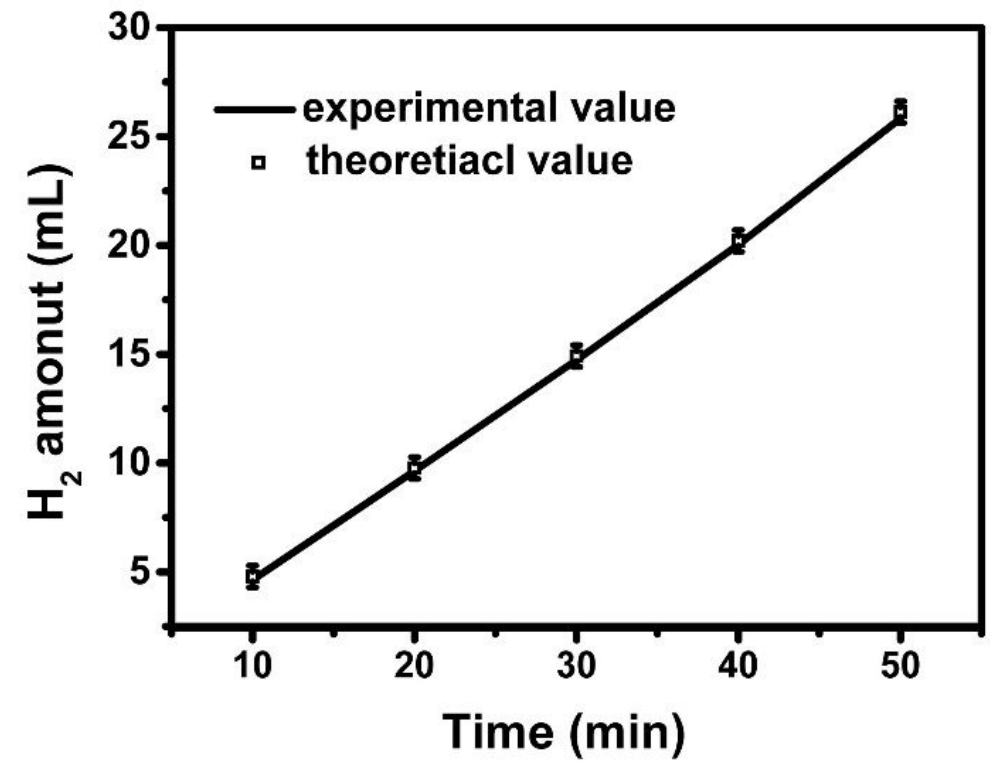

Figure S30. The Faradic efficiency of $1 \%\left\{\mathrm{PtW}_{6}\right\} / \mathrm{C}$. The FE of $\left\{\mathrm{PtW}_{6}\right\} / \mathrm{C}$ is nearly $100 \%$. 


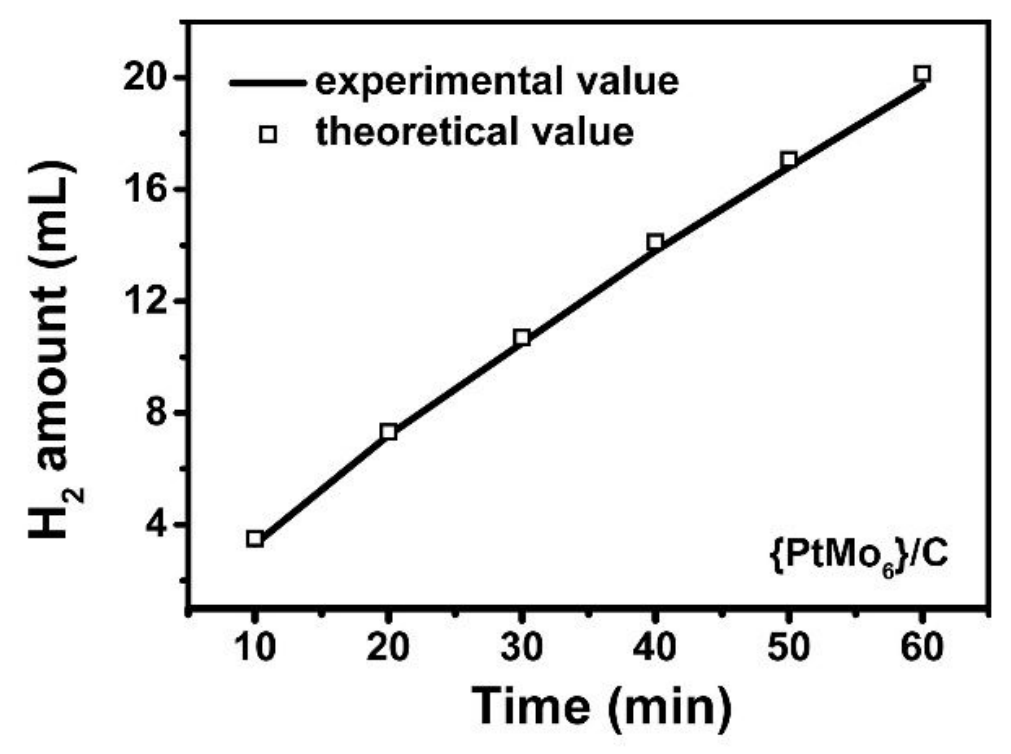

Figure S31. The Faradic efficiency of $1 \%\left\{\mathrm{PtMo}_{6}\right\} / \mathrm{C}$. The FE of $\left\{\mathrm{PtMo}_{6}\right\} / \mathrm{C}$ is nearly $100 \%$. 


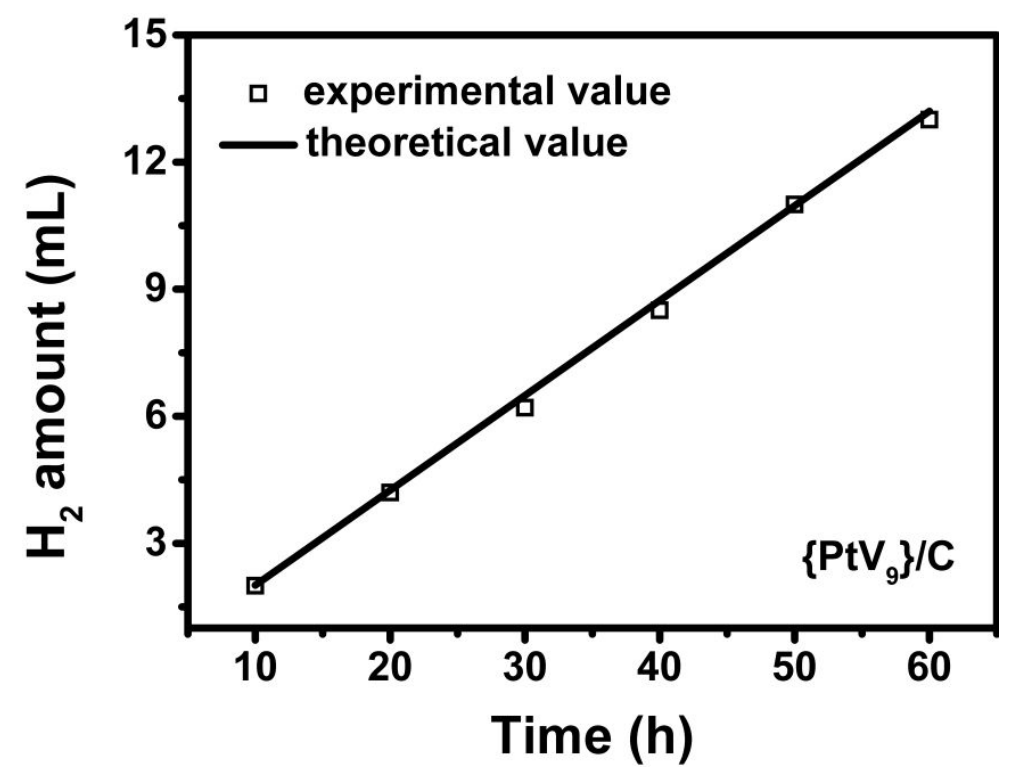

Figure S32. The Faradic efficiency of $1 \%\left\{\mathrm{PtV}_{9}\right\} / \mathrm{C}$. The FE of $\left\{\mathrm{PtV}_{9}\right\} / \mathrm{C}$ is nearly $100 \%$. 


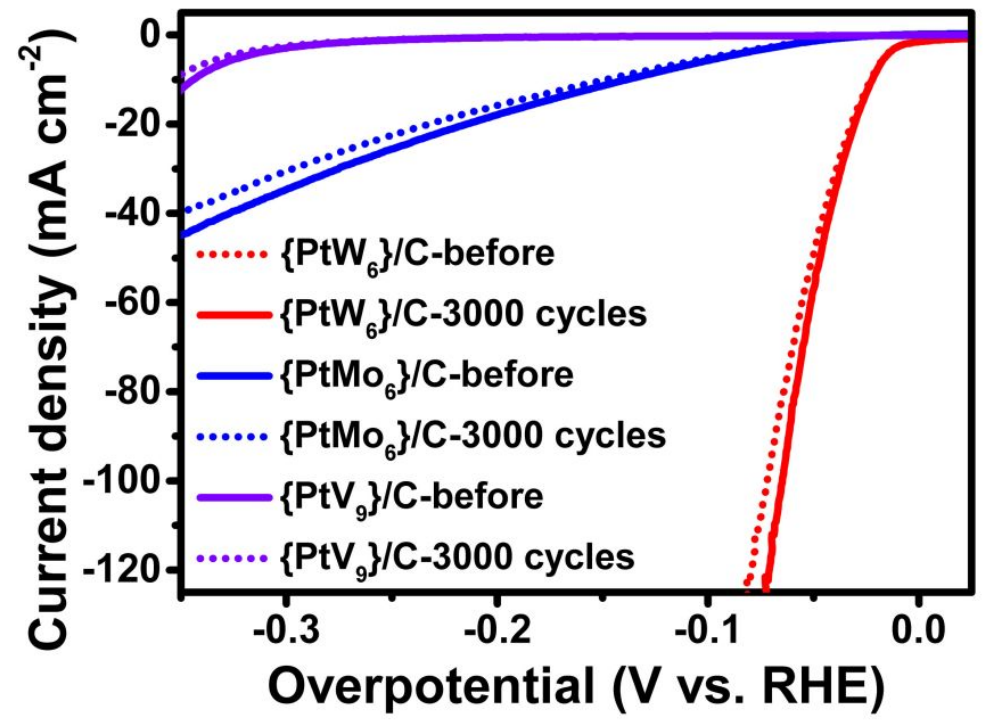

Figure S33. LSV curves of $\left\{\mathrm{PtW}_{6}\right\} / \mathrm{C},\left\{\mathrm{PtMo}_{6}\right\} / \mathrm{C}$ and $\left\{\mathrm{PtV}_{9}\right\} / \mathrm{C}$ before and after 3000 cycles of CV tes 


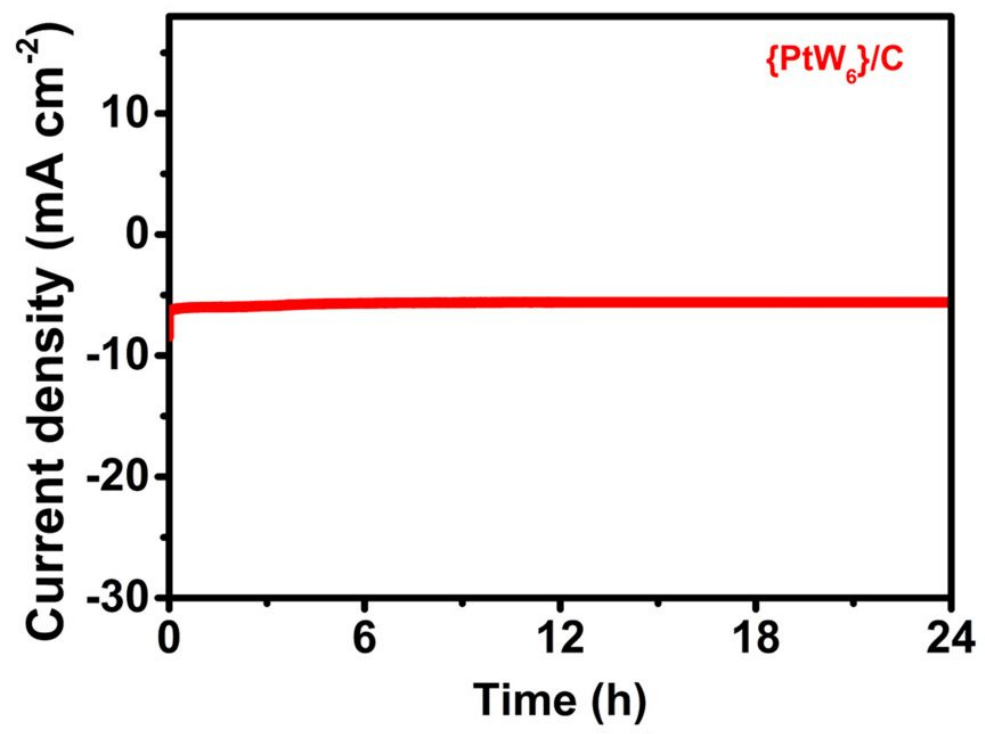

Figure S34. Time-dependent current density current of $1 \%\left\{\mathrm{PtW}_{6}\right\} / \mathrm{C}$ within $24 \mathrm{~h}$. 


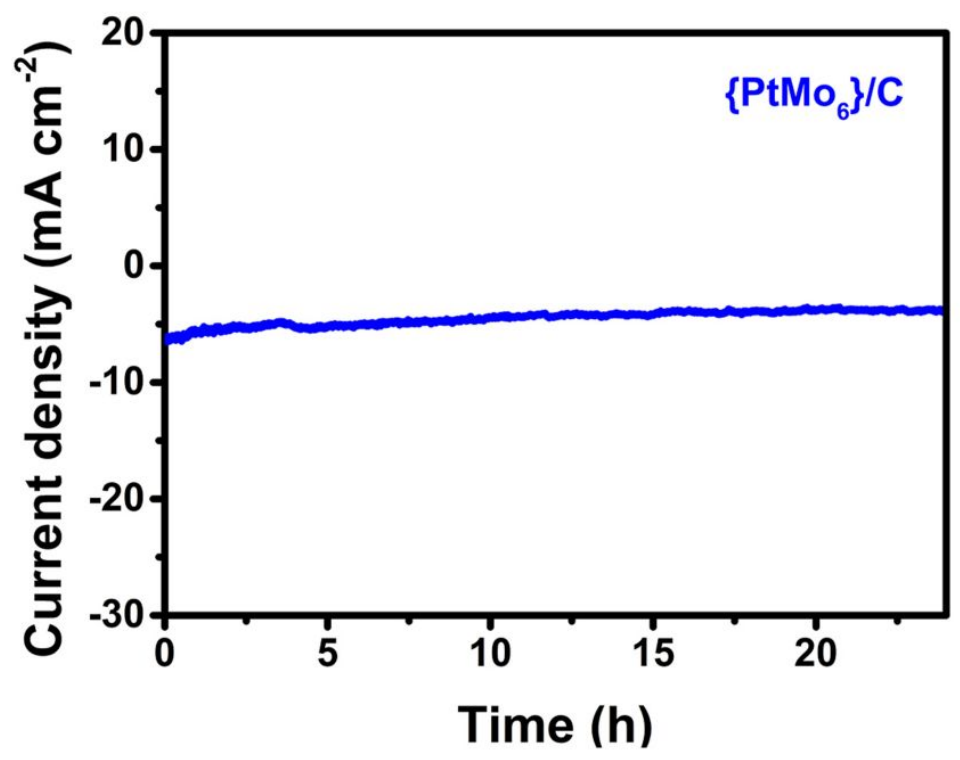

Figure S35. Time-dependent current density current of $1 \%\left\{\mathrm{PtMo}_{6}\right\} / \mathrm{C}$ within $24 \mathrm{~h}$. 


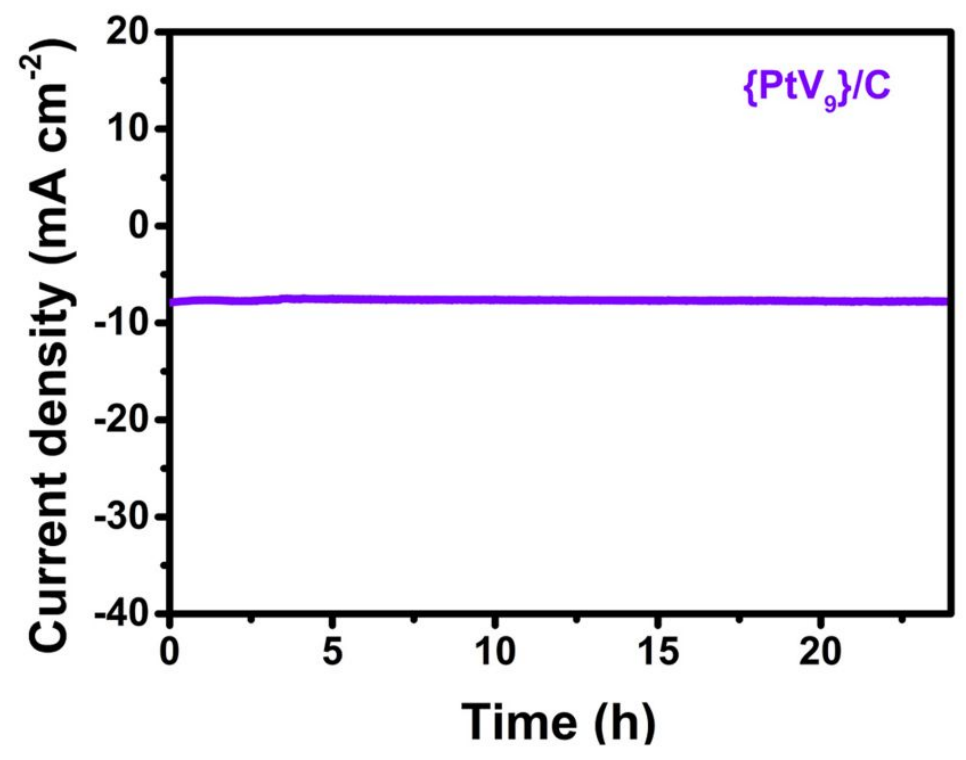

Figure S36. Time-dependent current density current of $1 \%\left\{\mathrm{PtV}_{9}\right\} / \mathrm{C}$ within $24 \mathrm{~h}$. 

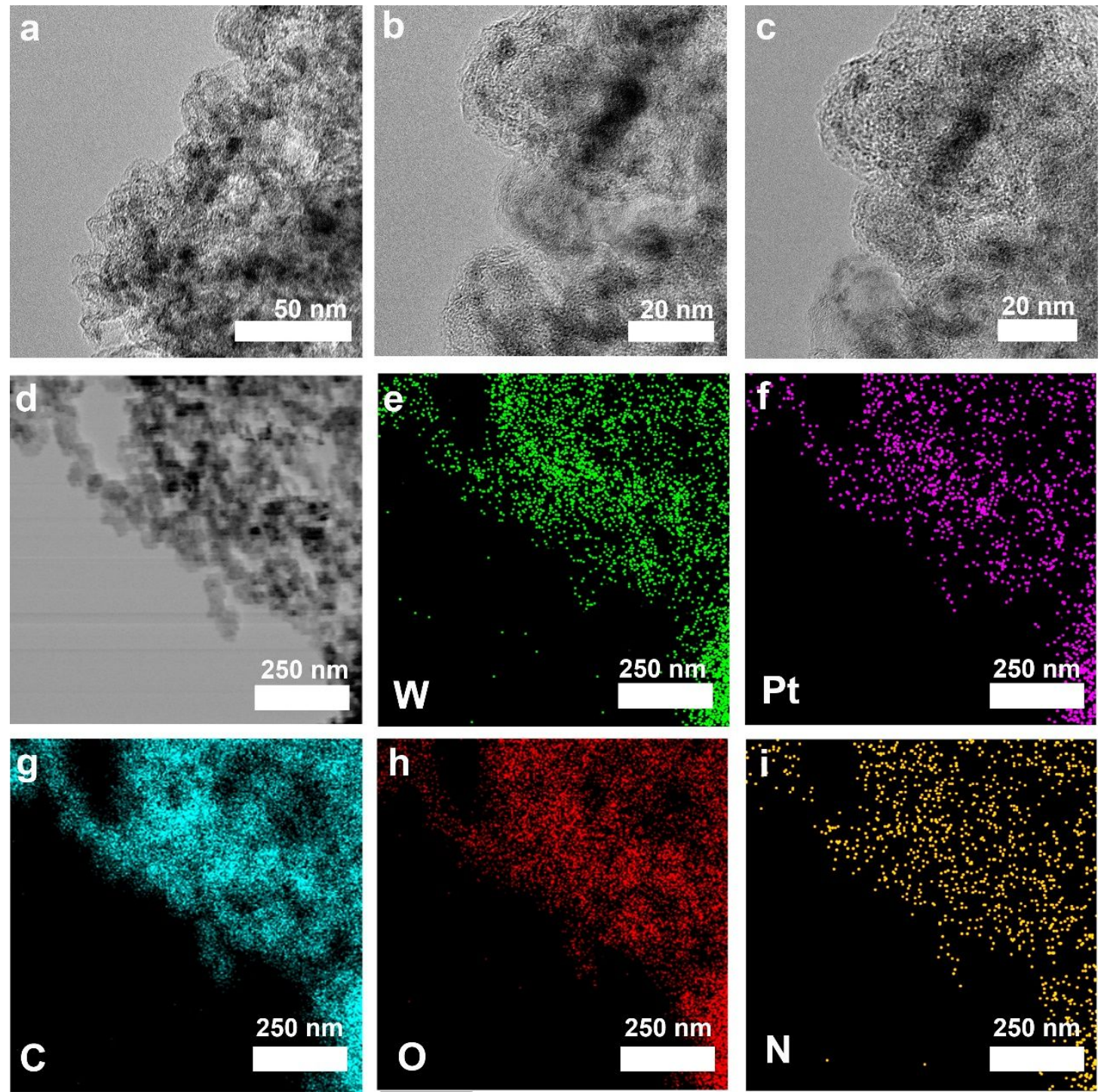

Figure S37. (a-c) TEM images of $1 \%\left\{\mathrm{PtW}_{6}\right\} / \mathrm{C}$ after electrochemical tests. (d-i) Elemental mapping of $1 \%\left\{\mathrm{PtW}_{6}\right\} / \mathrm{C}$ after electrochemical tests. 

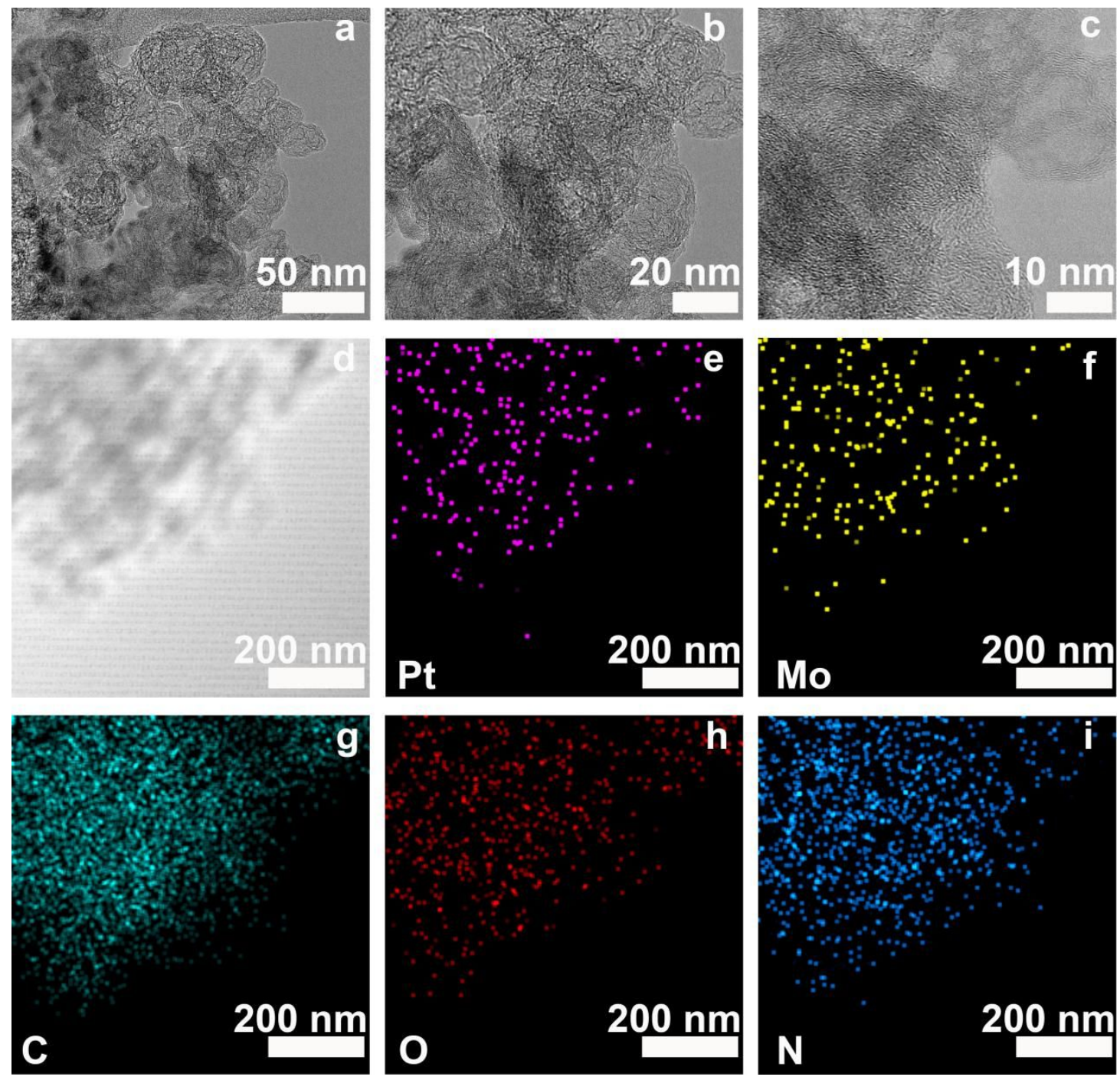

Figure S38. (a-c) TEM images of $1 \%\left\{\mathrm{PtMo}_{6}\right\} / \mathrm{C}$ after electrochemical tests. (d-i) Elemental mapping of $1 \%\left\{\mathrm{PtMo}_{6}\right\} / \mathrm{C}$ after electrochemical tests. 

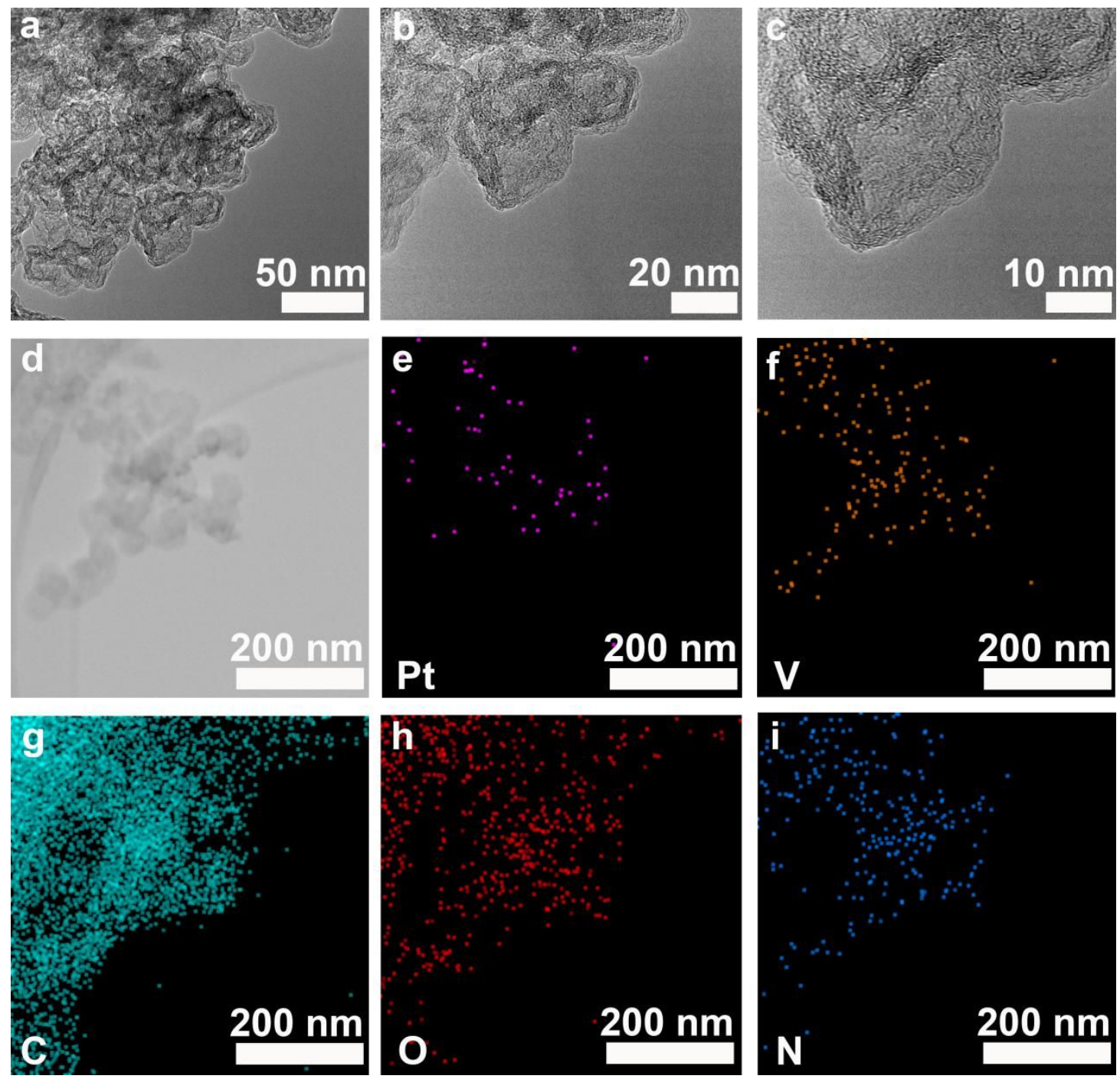

Figure S39. (a-c) TEM images of $1 \%\left\{\mathrm{PtV}_{9}\right\} / \mathrm{C}$ after electrochemical tests. (d-i) Elemental mapping of $1 \%\left\{\mathrm{PtV}_{9}\right\} / \mathrm{C}$ after electrochemical tests. 


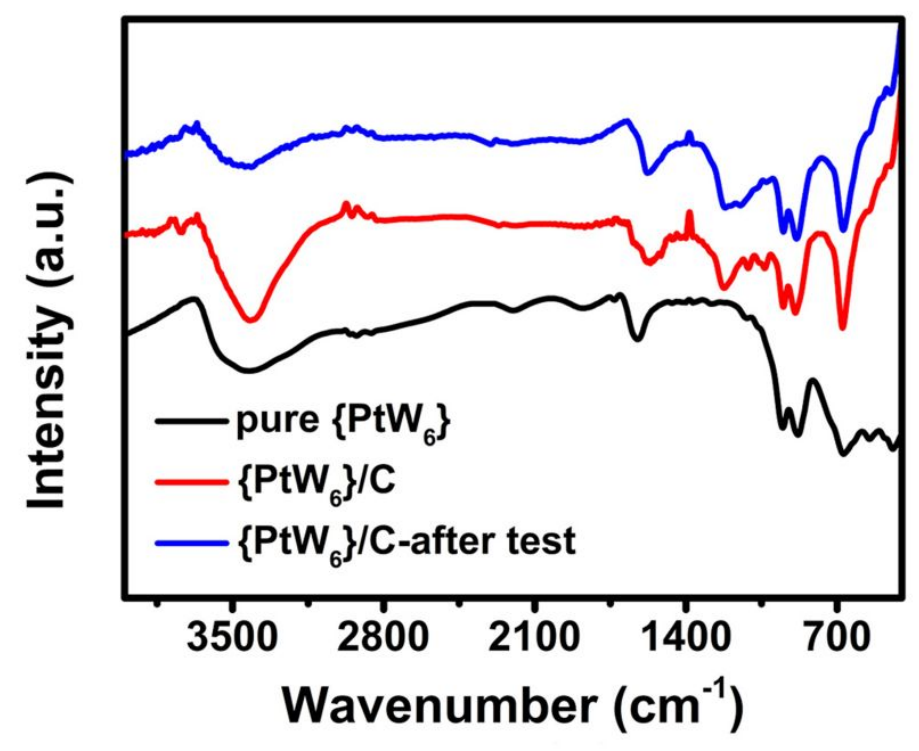

Figure S40. IR spectroscopy of pure molecule $\left\{\mathrm{PtW}_{6}\right\}, \quad\left\{\mathrm{PtW}_{6}\right\} / \mathrm{C}$ before electrochemical hydrogen evolution reaction and $\left\{\mathrm{PtW}_{6}\right\} / \mathrm{C}$ after electrochemical hydrogen evolution reaction. 


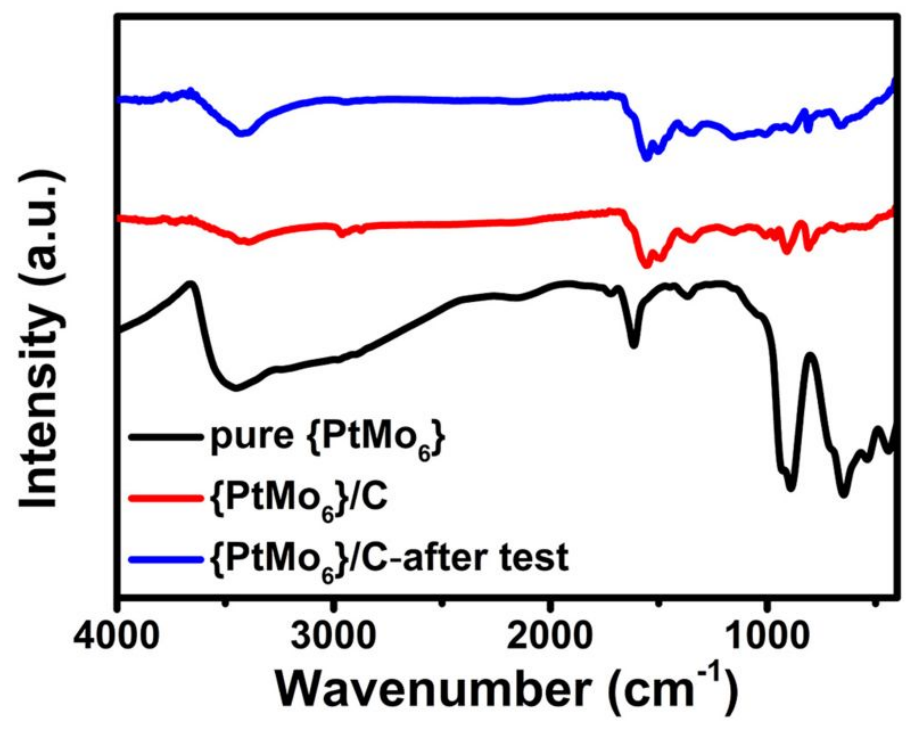

Figure S41. IR spectroscopy of pure molecule $\left\{\mathrm{PtMo}_{6}\right\},\left\{\mathrm{PtMo}_{6}\right\} / \mathrm{C}$ before electrochemical hydrogen evolution reaction and $\left\{\mathrm{PtMo}_{6}\right\} / \mathrm{C}$ after electrochemical hydrogen evolution reaction. 


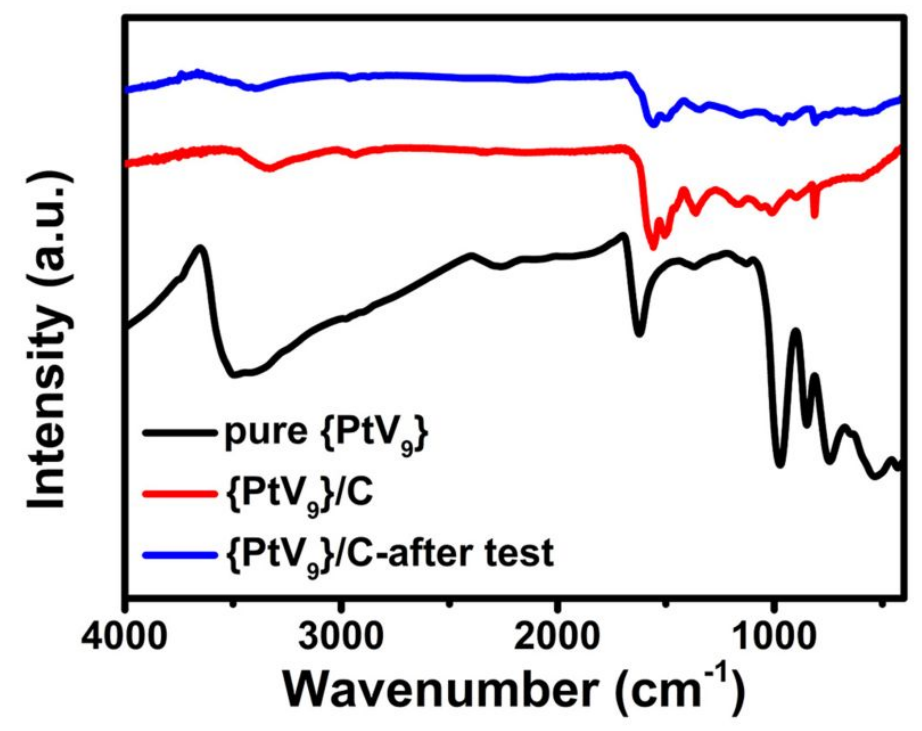

Figure S42. IR spectroscopy of pure molecule $\left\{\mathrm{PtV}_{9}\right\}, \quad\left\{\mathrm{PtV}_{9}\right\} / \mathrm{C}$ before electrochemical hydrogen evolution reaction and $\left\{\mathrm{PtV}_{9}\right\} / \mathrm{C}$ after electrochemical hydrogen evolution reaction. 


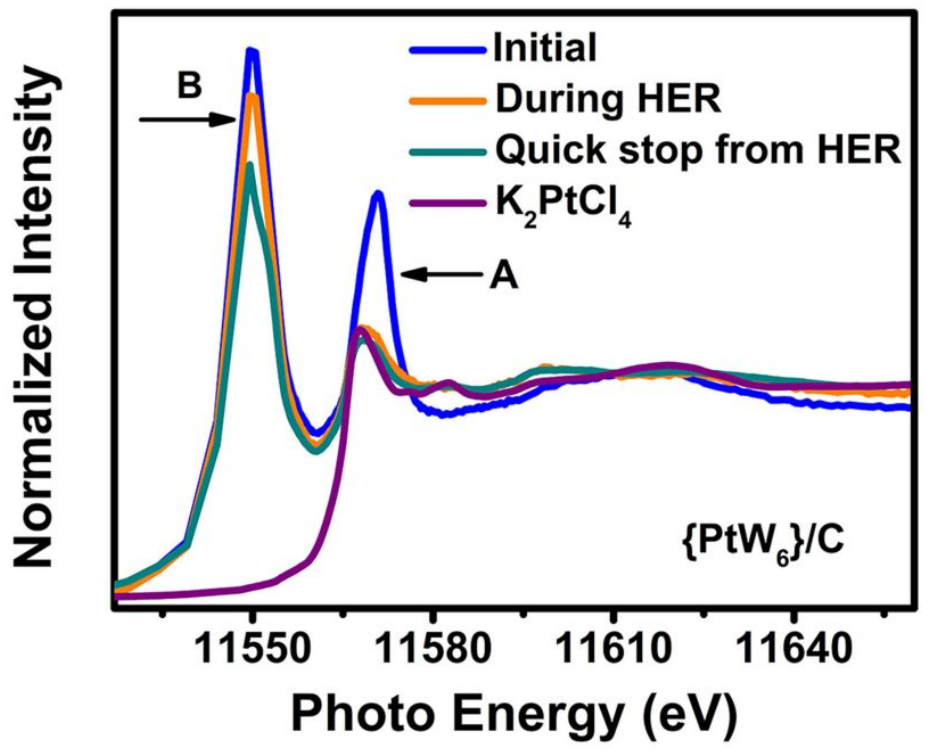

Figure S43. In-situ XANES spectra of the $1 \% \mathrm{PtW}_{6} \mathrm{O}_{24} / \mathrm{C}$ sample at $\mathrm{Pt} L_{3}$-edge. Feature $\mathrm{A}$ is attributed to $\mathrm{Pt} L_{3}$-edge and feature $\mathrm{B}$ is attributed to $\mathrm{W} L_{2}$-edge. 


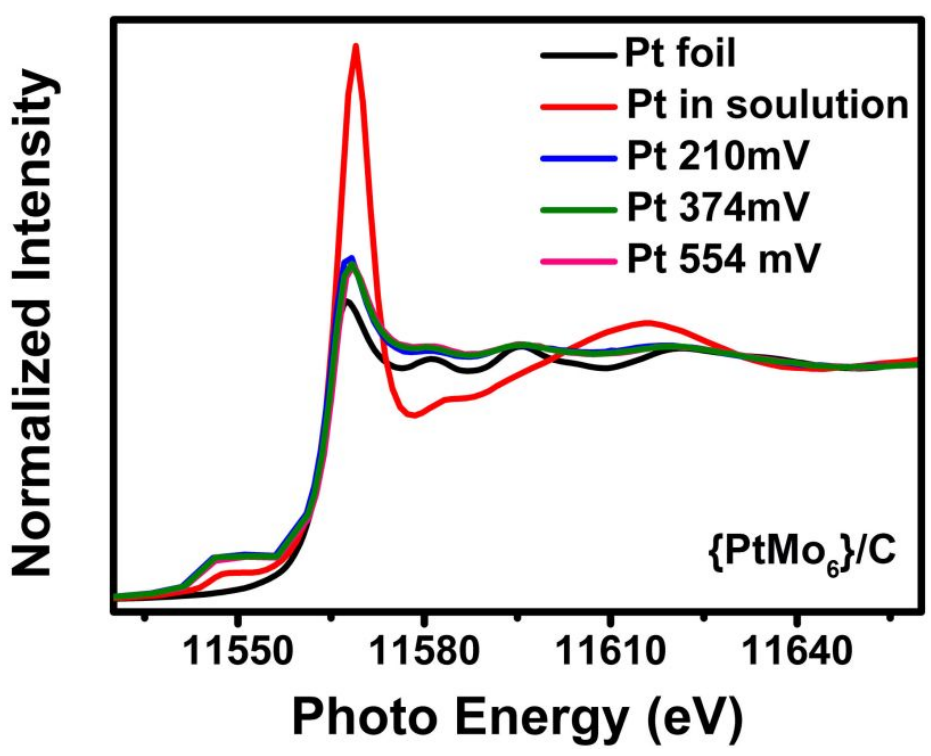

Figure S44. In-situ XANES spectra of the $\left\{\mathrm{PtMo}_{6}\right\} / \mathrm{C}$ sample at $\mathrm{Pt} L_{3}$-edge. 


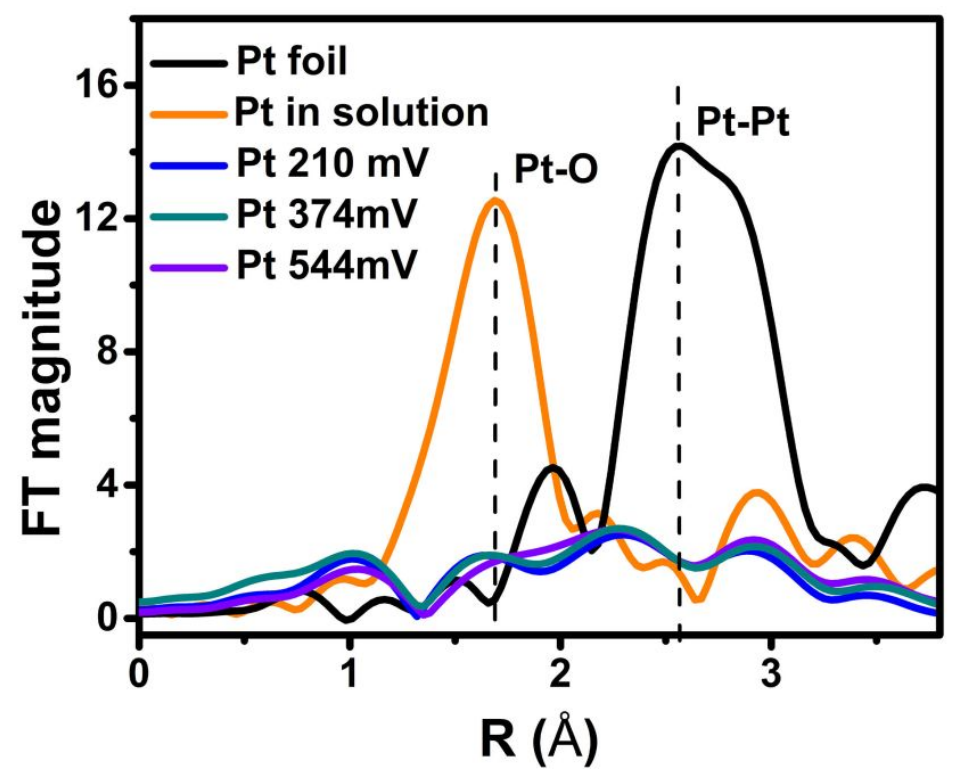

Figure S45. The Fourier transform of the EXAFS data of $\left\{\mathrm{PtMo}_{6}\right\} / \mathrm{C}$. 


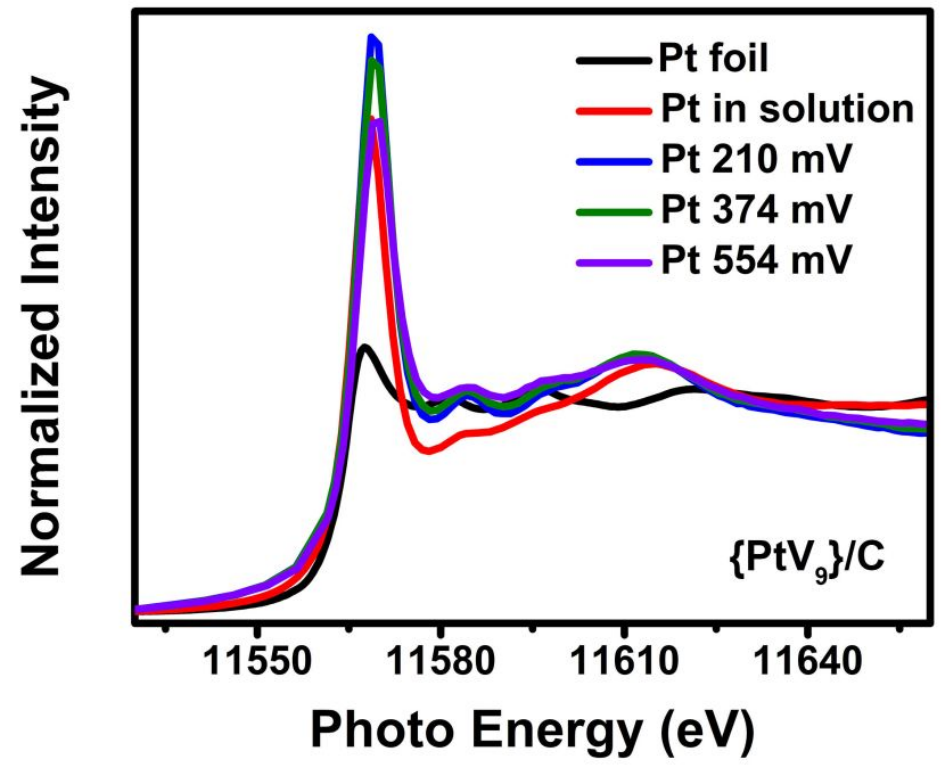

Figure S46. In-situ XANES spectra of the $\left\{\mathrm{PtV}_{9}\right\} / \mathrm{C}$ sample at $\mathrm{Pt} L_{3}$-edge. 


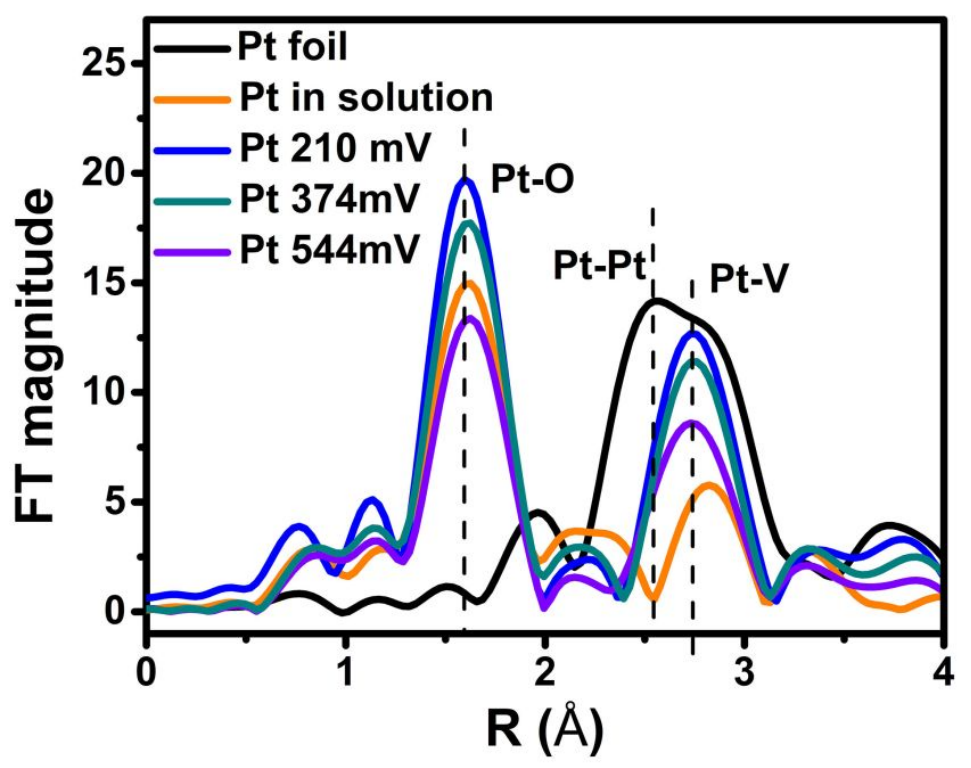

Figure S47. The Fourier transform of the EXAFS data of $\left\{\mathrm{PtV}_{9}\right\} / \mathrm{C}$. 

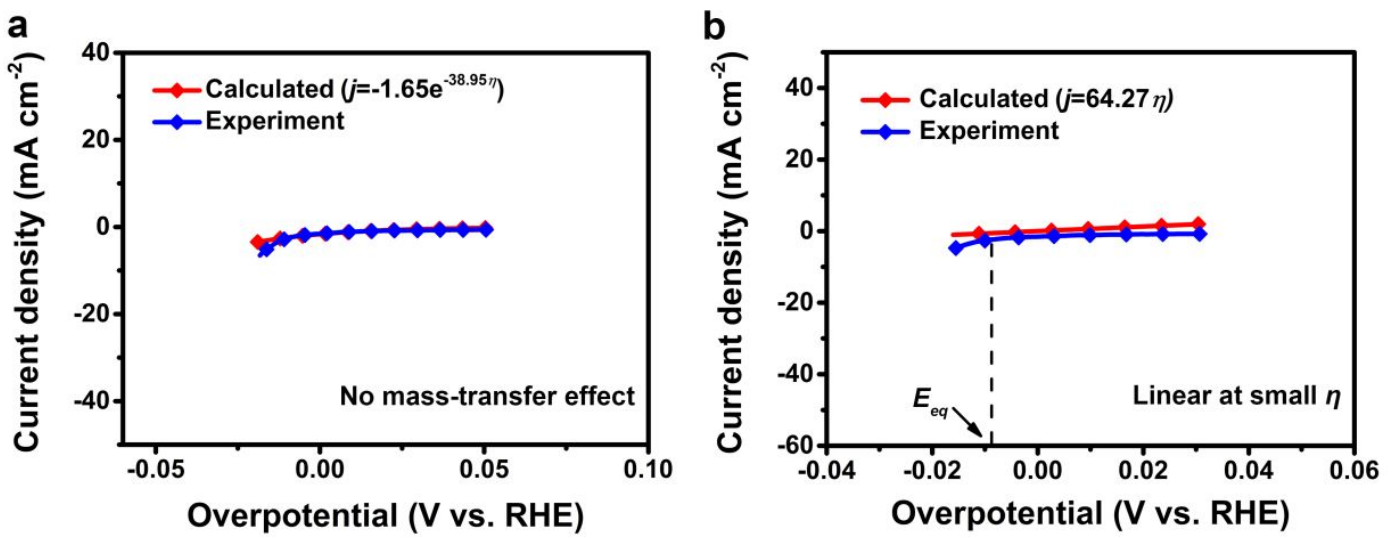

Figure S48. (a) The current density-overpotential diagram of Pt-O active center fitted by the Butler-Volmer equation, which is corrected by the equilibrium potential with no mass-transfer effect of $\left\{\mathrm{PtMo}_{6}\right\} / \mathrm{C}$ (red) and the experiment results of $\left\{\mathrm{PtW}_{6}\right\} / \mathrm{C}$ (blue). (b) The current density-overpotential diagram of Pt-O active center fitted by the ButlerVolmer equation, which is corrected by the equilibrium potential at small overpotential of $\left\{\mathrm{PtMo}_{6}\right\}$ (red) and the experiment results of $\left\{\mathrm{PtW}_{6}\right\} / \mathrm{C}$ (blue). Compared with the experimental data, it is found that the current density of $\mathrm{Pt}-\mathrm{O}$ active center in $\left\{\mathrm{PtMo}_{6}\right\} / \mathrm{C}$ with the overpotential basically the same trend. Here, we take $\left\{\mathrm{PtW}_{6}\right\} / \mathrm{C}$ as the standard, and assume that the transmission resistance of electrons on $\left\{\mathrm{PtW}_{6}\right\} / \mathrm{C}$ is zero. Then, the electrocatalytic activity of $\left\{\mathrm{PtW}_{6}\right\}$ can be considered as the electrocatalytic activity of the active center of the Pt-O bond. $\left\{\mathrm{PtMo}_{6}\right\}$ possesses the same active center Pt-O bond as $\left\{\mathrm{PtW}_{6}\right\}$, which is proved by DFT calculations. The potential difference caused by the support is

$$
\Delta E=E_{e q(\{\mathrm{PtMo} 6\})}-E_{e q(\{\mathrm{PtW} 6\})}=34.3 \mathrm{mV}-8.7 \mathrm{mV}=26.1 \mathrm{mV}
$$

(Equation S4)

then the potential of the active center of $\left\{\mathrm{PtMo}_{6}\right\}$ is

$$
E_{(\mathrm{Pt}-\mathrm{O})}=E_{(\{\mathrm{PtMo} 6\})^{-}}-\Delta E=E_{(\{\mathrm{PtMo} 6\})}-26.1 \mathrm{mV}
$$

(Equation S5)

Butler-Volmer Equation at small overpotential which is close to equilibrium potential was used as:

$$
i=-i_{0} f \eta
$$

Incorporating Equation S5 into the B-V equation (Equation S6) can be fitted to obtain the electrochemical behavior of the Pt-O active center of $\left\{\mathrm{PtMo}_{6}\right\} / \mathrm{C}$ was shown in Figure S48b. 

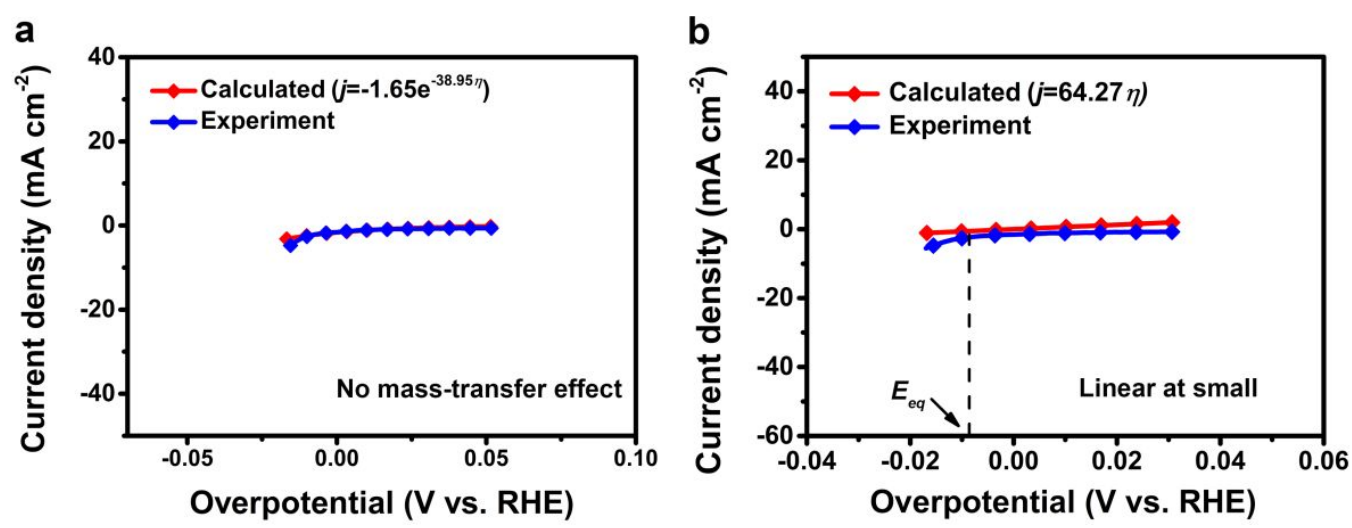

Figure S49. (a) The current density-overpotential diagram of Pt-O active center fitted by the Butler-Volmer equation, which is corrected by the equilibrium potential with no mass-transfer effect of $\left\{\mathrm{PtV}_{9}\right\} / \mathrm{C}$ (red) and the experiment results of $\left\{\mathrm{PtW}_{6}\right\} / \mathrm{C}$ (blue). (b) The current density-overpotential diagram of Pt-O active center fitted by the ButlerVolmer equation, which is corrected by the equilibrium potential at small overpotential of $\left\{\mathrm{PtV}_{9}\right\} / \mathrm{C}$ (red) and the experiment results of $\left\{\mathrm{PtW}_{6}\right\} / \mathrm{C}$ (blue). Compared with the experimental data, it is found that the current density of $\mathrm{Pt}-\mathrm{O}$ active center in $\left\{\mathrm{PtV}_{9}\right\} / \mathrm{C}$ with the overpotential basically the same trend. Here, the electrochemical behavior of the Pt-O bond active center in $\left\{\mathrm{PtV}_{9}\right\}$ is fitted by the $\mathrm{B}-\mathrm{V}$ equation with $\left\{\mathrm{PtW}_{6}\right\}$ as the standard.

$$
\Delta E=E_{e q(\{\mathrm{PtV} 9\})}-E_{e q(\{\mathrm{PtW} 6\})}=261.4 \mathrm{mV}-8.7 \mathrm{mV}=252.7 \mathrm{mV}
$$

(Equation S7)

And then, the potential of the active center of $\left\{\mathrm{PtV}_{9}\right\}$ is as follows.

$$
\left.\left.E_{(\mathrm{Pt}-\mathrm{O})}=E_{(\{\mathrm{PtV} 9\})}\right)^{-} \Delta E=E_{(\{\mathrm{PtMo}\}}\right)^{-}-252.7 \mathrm{mV}
$$

(Equation S8)

Incorporating Equation S8 into the B-V equation (Equation S6) can be fitted to obtain the electrochemical behavior of the Pt-O active center of $\left\{\mathrm{PtV}_{9}\right\} / \mathrm{C}$ was shown in Figure S49b. 


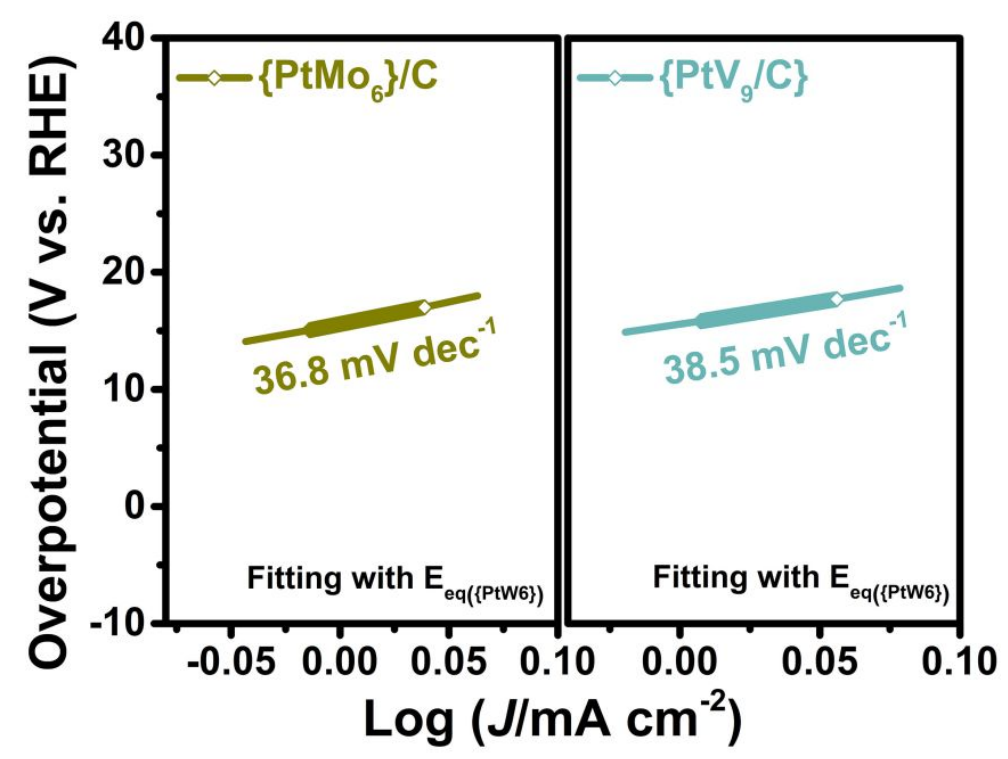

Figure S50. The Tafel slope of Pt-O active center fitted by the Butler-Volmer equation and Tafel equation which is corrected by the equilibrium potential at small overpotential of $\left\{\mathrm{PtMo}_{6}\right\}$ and $\left\{\mathrm{PtV}_{9}\right\}$ and the experiment results of $\left\{\mathrm{PtW}_{6}\right\} / \mathrm{C}$. 


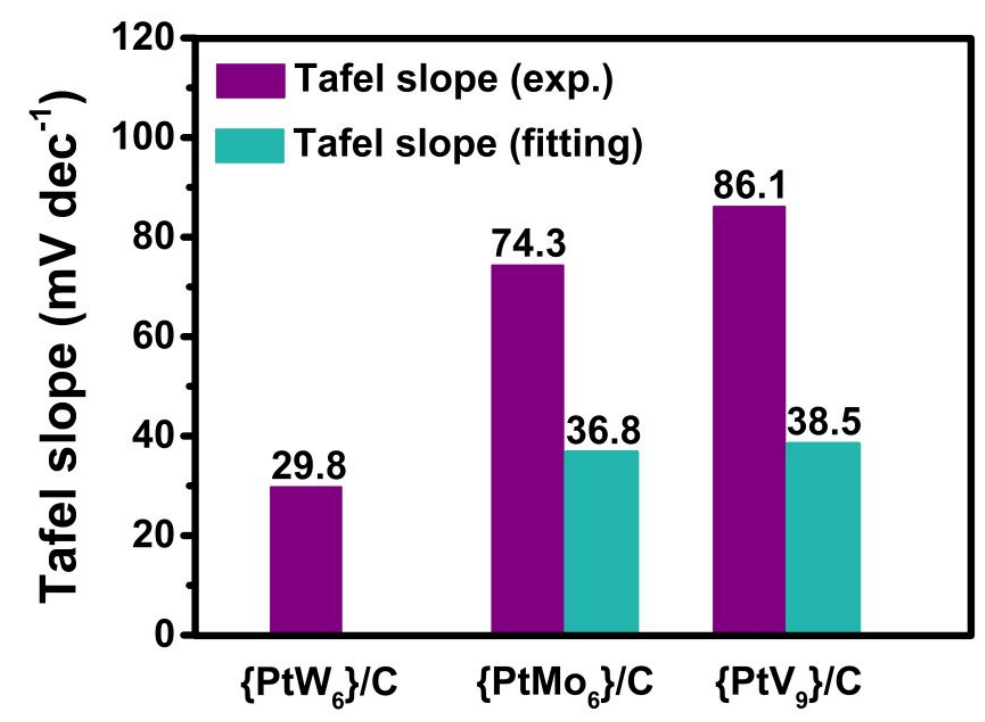

Figure S51. The Tafel slope of Pt-O active center in $\left\{\mathrm{PtW}_{6}\right\} / \mathrm{C},\left\{\mathrm{PtMo}_{6}\right\} / \mathrm{C}$, and $\left\{\mathrm{PtV}_{9}\right\} / \mathrm{C}$.

Based on the above experiments, the Butler-Volmer equation was used to describe electrochemical behavior of the Pt-O bond active center in different POMs. As shown in Figure S48-S49, Equation S4-S8, these experimental current densities of $\left\{\mathrm{PtW}_{6}\right\} / \mathrm{C}$, $\left\{\mathrm{PtMo}_{6}\right\} / \mathrm{C}$ and $\left\{\mathrm{PtV}_{9}\right\} / \mathrm{C}$ are 2.6, 0.26 and $0.23 \mathrm{~mA} \mathrm{~cm}{ }^{-2}$, respectively, at the overpotential of $10 \mathrm{mV}$. The fitted current densities of $\left\{\mathrm{PtMo}_{6}\right\} / \mathrm{C}$ and $\left\{\mathrm{PtV}_{9}\right\} / \mathrm{C}$ are 0.65 and $0.64 \mathrm{~mA} \mathrm{~cm}^{-2}$ at $10 \mathrm{mV}$, respectively, which are closer to the experiment current density of $\left\{\mathrm{PtW}_{6}\right\} / \mathrm{C}$. As shown in Figures S50-S51, these fitted tafel slopes of $\left\{\mathrm{PtMo}_{6}\right\} / \mathrm{C}$ and $\left\{\mathrm{PtV}_{9}\right\} / \mathrm{C}$ are $36.8 \mathrm{mV} \mathrm{dec}^{-1}$ and $38.5 \mathrm{mV} \mathrm{dec}^{-1}$, respectively, close to the experimental Tafel slope of $\left\{\mathrm{PtW}_{6}\right\} / \mathrm{C}\left(29.8 \mathrm{mV} \mathrm{dec}^{-1}\right)$, meaning that the VolmerTafel is the real rate-determined step in the reaction. Above results show that the support has a significant impact on the activity of the Pt-O active center, and if the influence of the support can be deducted, the three Pt-based catalysts will show similar activities and kinetics. 


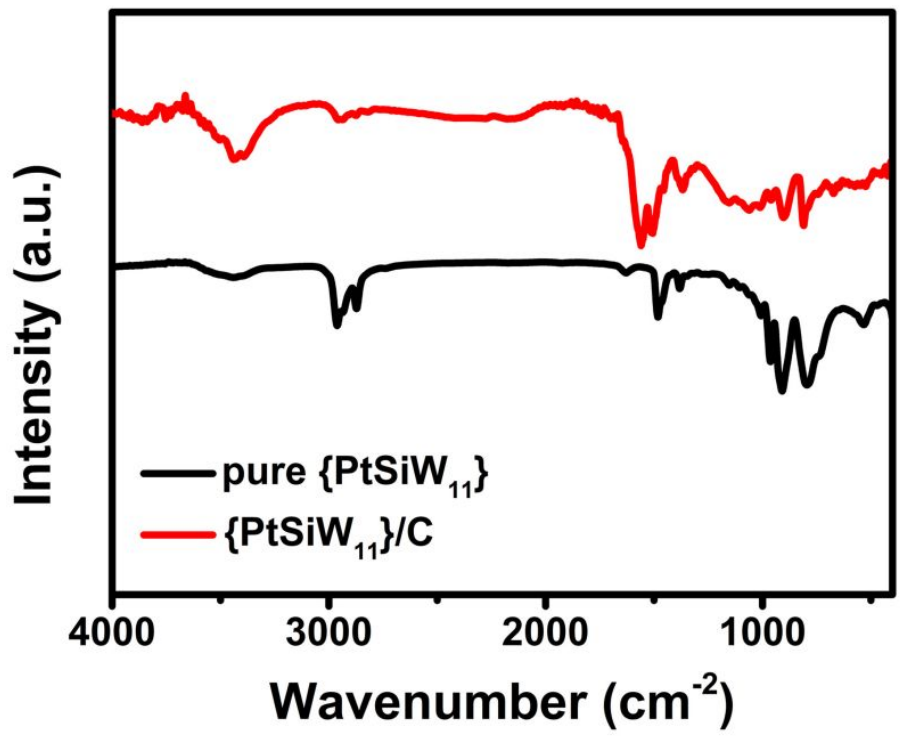

Figure S52. The IR curves of pure $\left\{\mathrm{PtSiW}_{11}\right\}$ and $\left\{\mathrm{PtSiW}_{11}\right\} / \mathrm{C}$ which means the structure of $\left\{\mathrm{PtSiW}_{11}\right\} / \mathrm{C}$ remain well during the materialization process. 

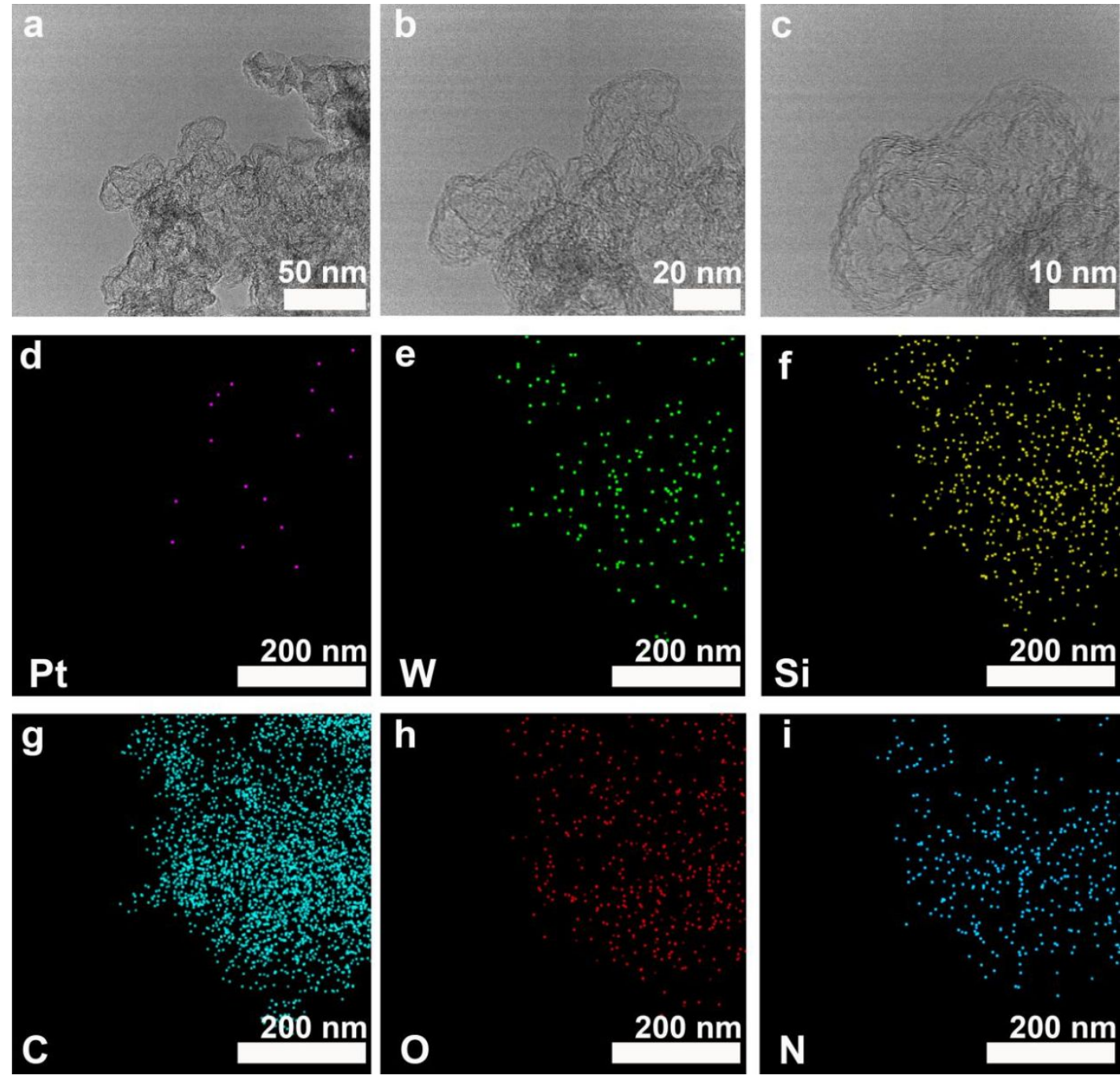

Figure S53. (a-c) TEM of $1 \%\left\{\mathrm{PtSiW}_{11}\right\} / \mathrm{C}$. (d-i) Element mapping of $1 \% 1 \%$ $\left\{\mathrm{PtSiW}_{11}\right\} / \mathrm{C}, \mathrm{Pt}$ (d), W (e), Si (f), C (g), $\mathrm{O}$ (h) and $\mathrm{N}$ (i). TEM images show there are not obviously aggregation of particles, meaning that the $\left\{\mathrm{PtSiW}_{11}\right\}$ molecules were uniformly dispersed on the Ketjen black carbon. 


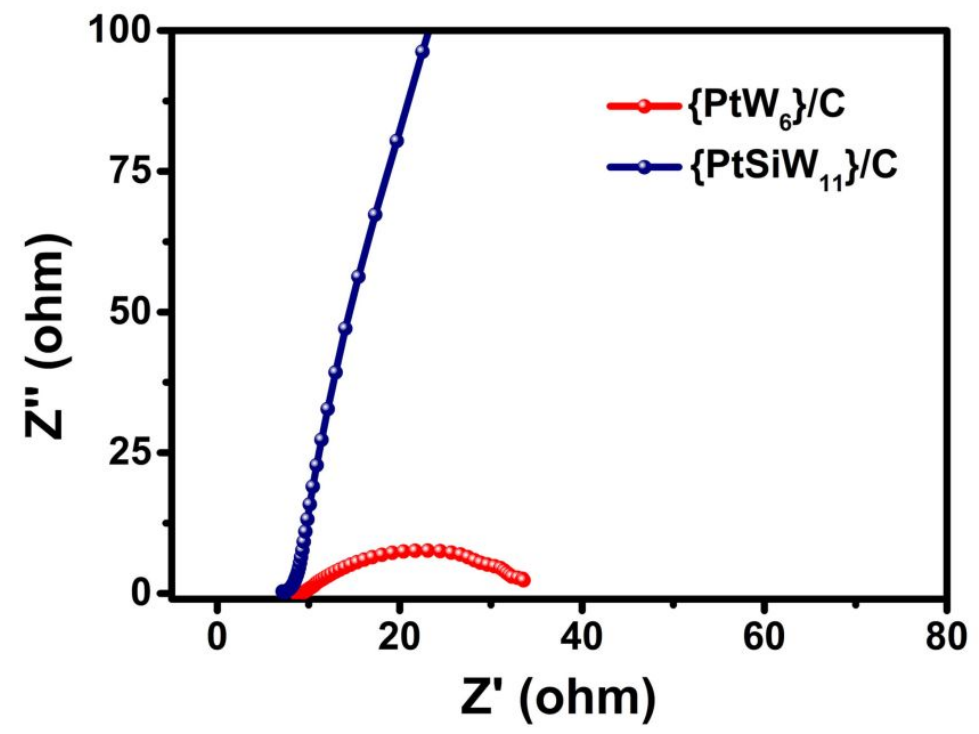

Figure S54. The Electrochemical impedance spectroscopy (EIS) of $\left\{\mathrm{PtW}_{6}\right\} / \mathrm{C}$ and $\left\{\mathrm{PtSiW}_{11}\right\} / \mathrm{C}$ at overpotential of $40 \mathrm{mV}$. 


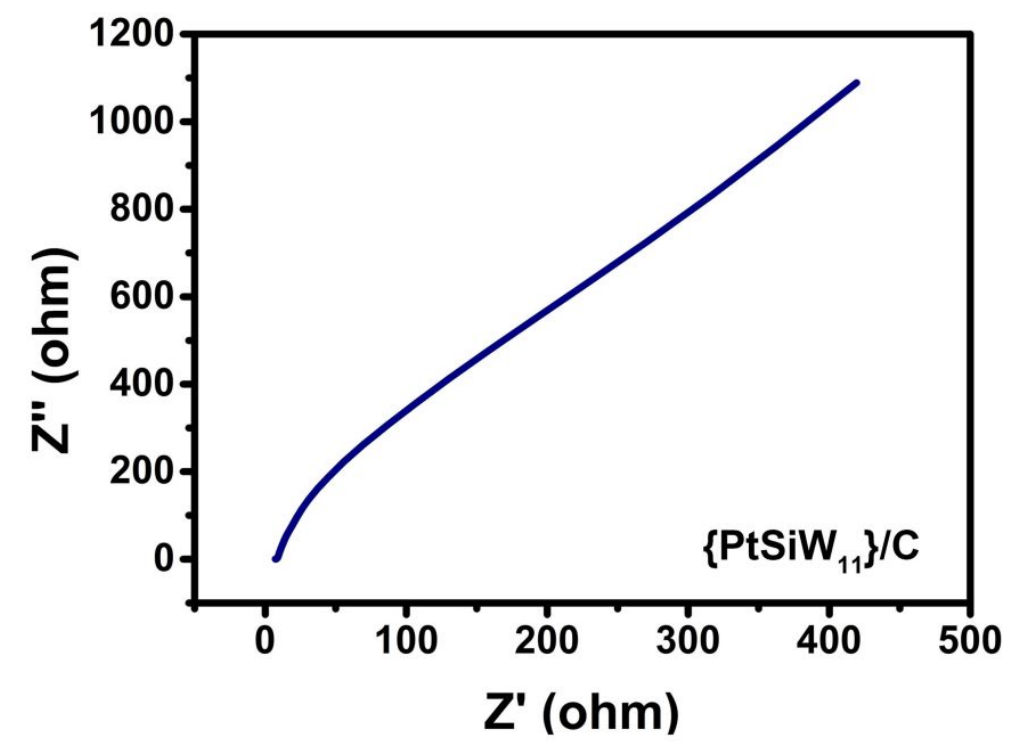

Figure S55. The complete data of electrochemical impedance spectroscopy (EIS) of $\left\{\mathrm{PtSiW}_{11}\right\} / \mathrm{C}$ at overpotential of $40 \mathrm{mV}$. 


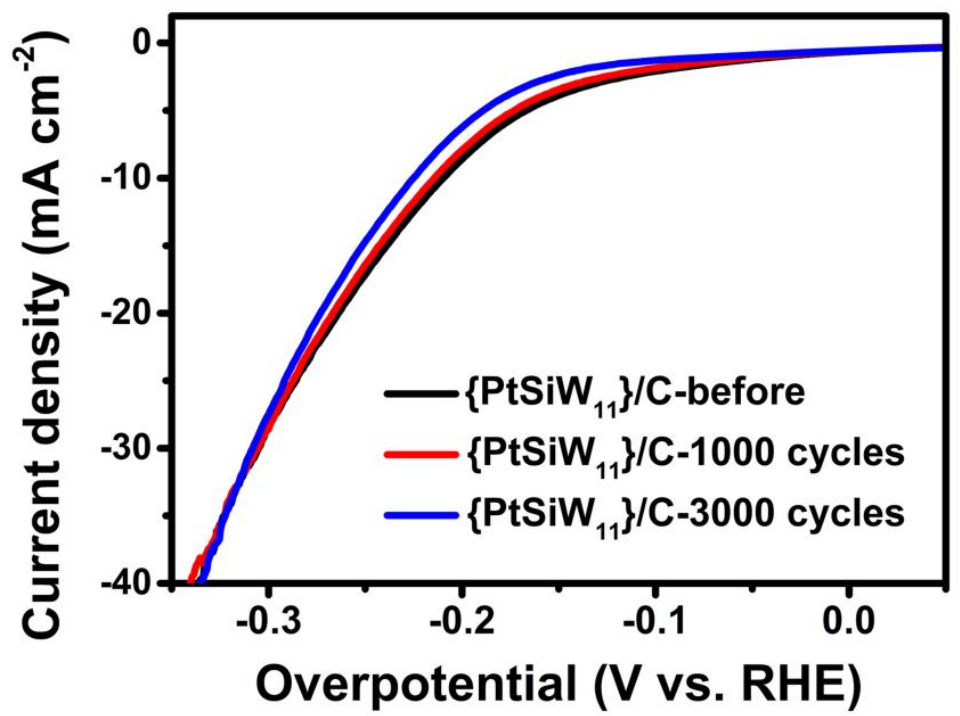

Figure S56. LSV curves of $\left\{\mathrm{PtSiW}_{11}\right\} / \mathrm{C}$ before and after 3000 cycles of CV test. 

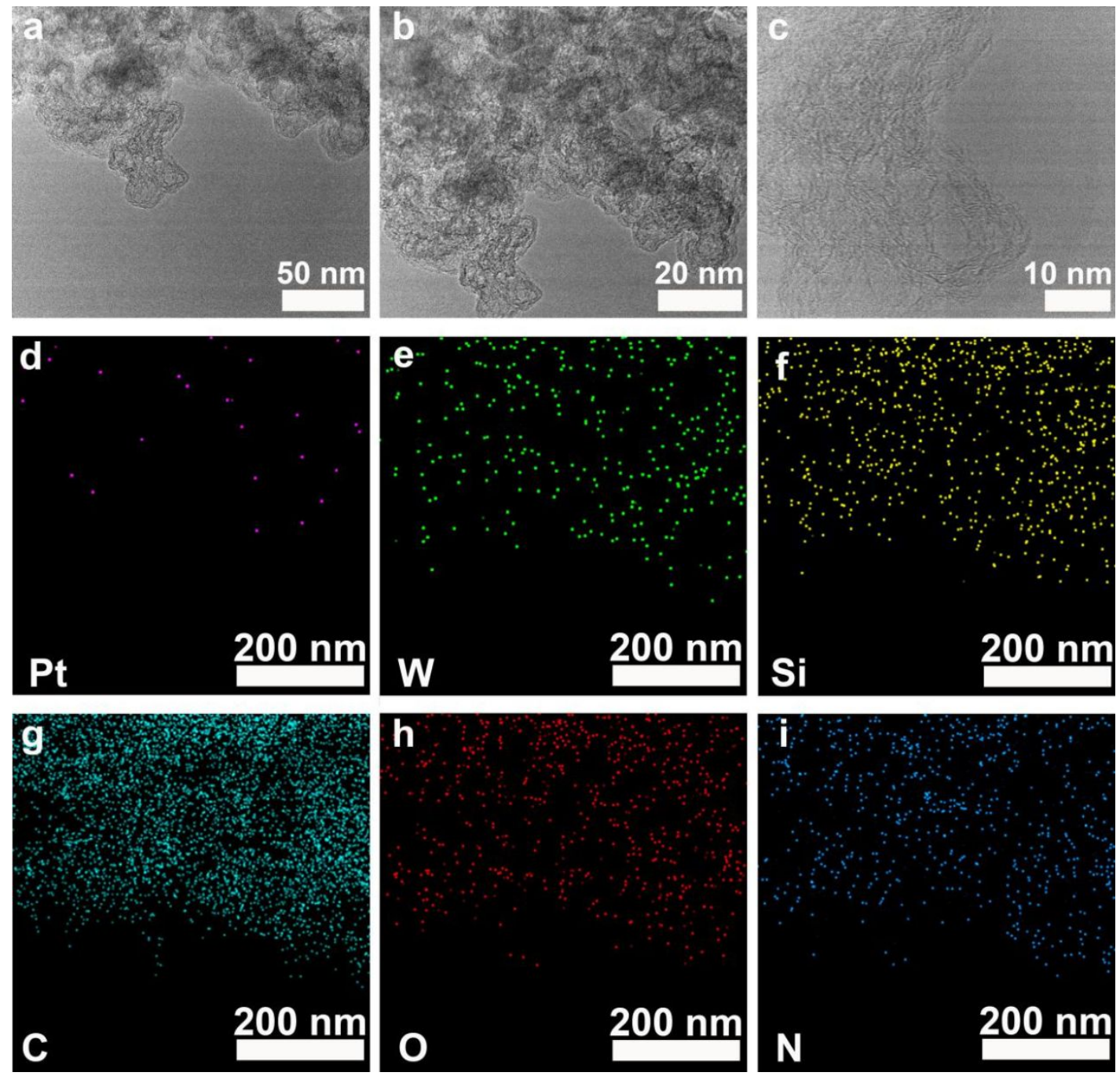

Figure S57. (a-c) TEM images of $1 \%\left\{\mathrm{PtSiW}_{11}\right\} / \mathrm{C}$ after electrochemical tests. (d-i) Elemental mapping of $1 \%\left\{\mathrm{PtSiW}_{11}\right\} / \mathrm{C}$ after electrochemical tests. $\mathrm{Pt}(\mathbf{d}), \mathrm{W}$ (e), $\mathrm{Si}$ (f), $\mathrm{C}(\mathrm{g}), \mathbf{O}(\mathbf{h})$ and $\mathrm{N}(\mathbf{i})$ 


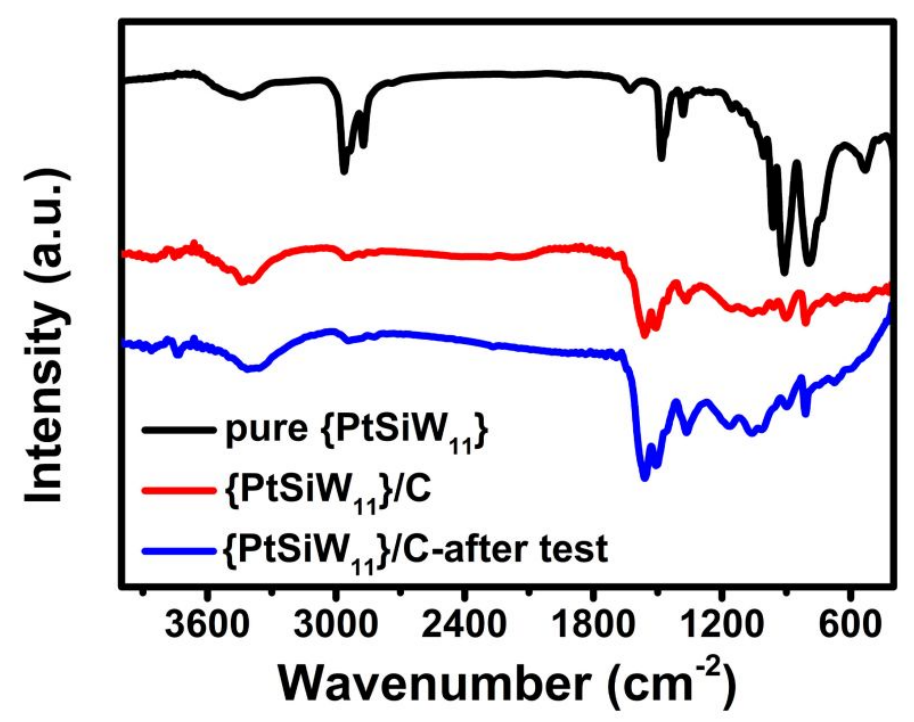

Figure S58. IR spectroscopy of pure molecule $\left\{\mathrm{PtSiW}_{11}\right\},\left\{\mathrm{PtSiW}_{11}\right\} / \mathrm{C}$ before electrochemical hydrogen evolution reaction and $\left\{\mathrm{PtSiW}_{11}\right\} / \mathrm{C}$ after electrochemical hydrogen evolution reaction. 


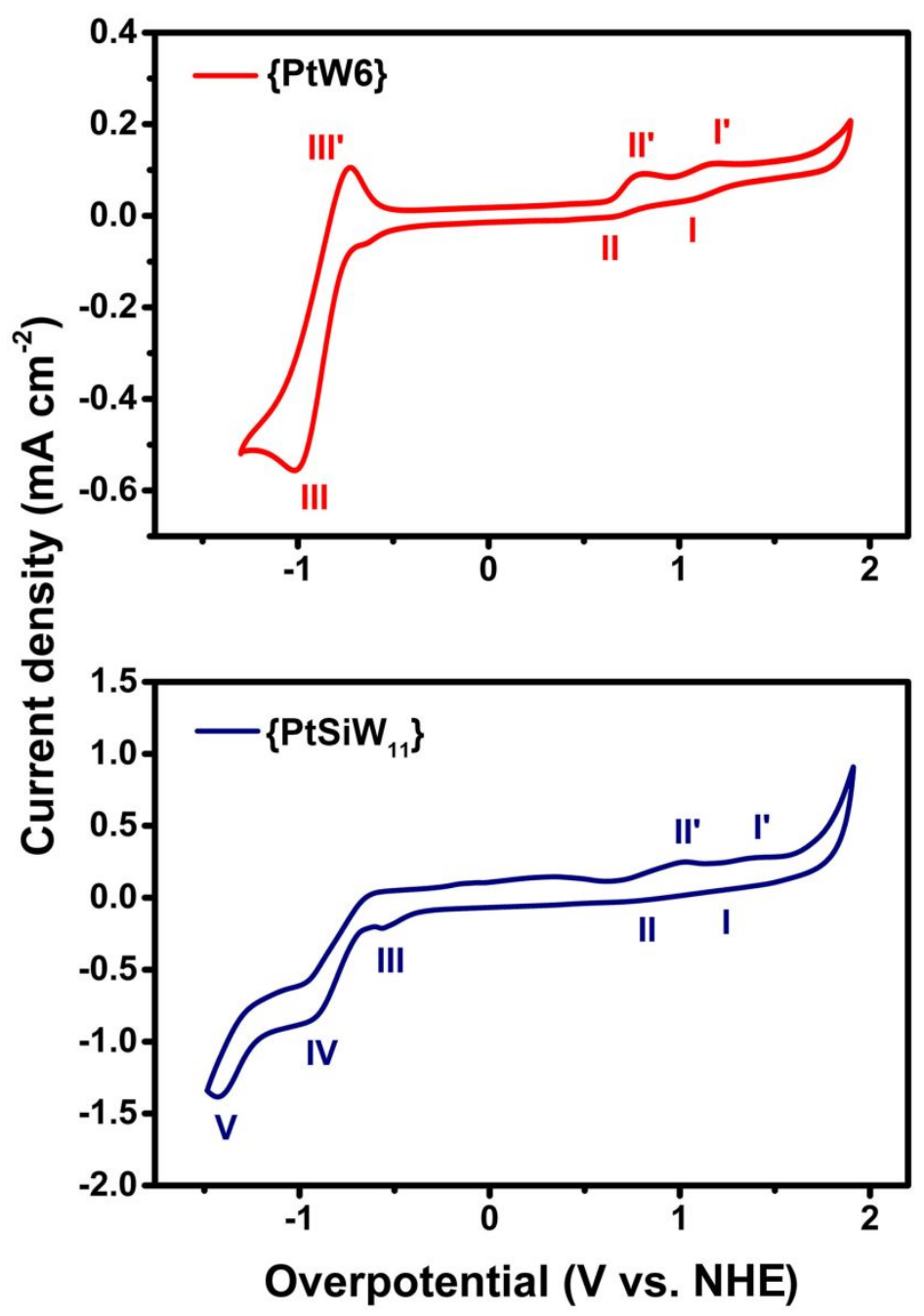

Figure S59. The cycle voltammetry of $\left\{\mathrm{PtW}_{6}\right\}$ (red) and $\left\{\mathrm{PtSiW}_{11}\right\}$ (Navy) in $\mathrm{N}_{2^{-}}$ saturated acetonitrile at the overpotential of $40 \mathrm{mV}$. 
Supplementary Tables

Supplementary Table 1 The EDS result of $\left\{\mathrm{PtW}_{6}\right\},\left\{\mathrm{PtMo}_{6}\right\}$ and $\left\{\mathrm{PtV}_{9}\right\}$.

\begin{tabular}{|c|c|c|}
\hline Samples & $\begin{array}{c}\text { Platinum content } \\
(\mathbf{w t} \%)\end{array}$ & $\begin{array}{c}\text { Metal } \\
(\mathbf{w t} \%)\end{array}$ \\
\hline $\mathbf{1 \%}\left\{\mathbf{P t W}_{\mathbf{6}}\right\} / \mathrm{C}$ & 0.95 & 5.37 \\
\hline $\mathbf{1 \%}\left\{\mathbf{P t M o}_{\mathbf{6}}\right\} / \mathbf{C}$ & 1.0 & 2.95 \\
\hline $\mathbf{1 \%}\left\{\mathbf{P t V}_{\mathbf{9}}\right\} / \mathbf{C}$ & 1.1 & 1.72 \\
\hline
\end{tabular}


Supplementary Table 2 The EDS result of Pt content in $\{\mathrm{PtSiW} 11\} / \mathrm{C}$.

\begin{tabular}{|c|c|c|}
\hline Samples & $\begin{array}{c}\text { Platinum content } \\
(\mathbf{w t} \%)\end{array}$ & $\begin{array}{c}\text { Tungsten } \\
\mathbf{( w t \% )}\end{array}$ \\
\hline $\mathbf{1 \%}\left\{\mathrm{PtSiW}_{11}\right\} / \mathrm{C}$ & 0.97 & 10.06 \\
\hline
\end{tabular}

